\title{
NUMERICAL STUDY OF THE HEAT TRANSFER PHENOMENON OF A RECTANGULAR PLATE INCLUDING VOID, NOTCH USING FINITE DIFFERENCE TECHNIQUE
}

\author{
S.K. DEB NATH* \\ Computational Materials Research Initiative \\ Institute for Materials Research \\ Tohoku University, JAPAN \\ E-mail: sankar_20005@yahoo.com \\ N.K. PEYADA \\ Department of Aerospace Engineering \\ Indian Institute of Technology \\ Kharagpur, INDIA
}

\begin{abstract}
In the present study, we have developed a code using Matlab software for solving a rectangular aluminum plate having void, notch, at different boundary conditions discretizing a two dimensional (2D) heat conduction equation by the finite difference technique. We have solved a $2 \mathrm{D}$ mixed boundary heat conduction problem analytically using Fourier integrals (Deb Nath et al., 2006; 2007; 2007; Deb Nath and Ahmed, 2008; Deb Nath, 2008; Deb Nath and Afsar, 2009; Deb Nath and Ahmed, 2009; 2009; Deb Nath et al., 2010; Deb Nath, 2013) and the same problem is also solved using the present code developed by the finite difference technique (Ahmed et al., 2005; Deb Nath, 2002; Deb Nath et al., 2008; Ahmed and Deb Nath, 2009; Deb Nath et al., 2011; Mohiuddin et al., 2012). To verify the soundness of the present heat conduction code results using the finite difference method, the distribution of temperature at some sections of a $2 \mathrm{D}$ heated plate obtained by the analytical method is compared with those of the plate obtained by the present finite difference method. Interpolation technique is used as an example when the boundary of the plate does not pass through the discretized grid points of the plate. Sometimes hot and cold fluids are passed through rectangular channels in industries and many types of technical equipment. The distribution of temperature of plates including notches, slots with different temperature boundary conditions are studied. Transient heat transfer in several pure metallic plates is also studied to find out the required time to reach equilibrium temperature. So, this study will help find design parameters of such structures.
\end{abstract}

Key words: transient, steady state, finite-difference method, analytical method, rectangular plate, void, notch

\section{Introduction}

Applications involving thermal conduction occur in many areas of science and be design (Siegel and Howell, 1972; Özisik, 1989), in power generation (Burmeister, 1993), glass manufacturing (Siegel and Howell, 1972) and astrophysics (Jaeger, 1950; Battaner, 1996). Simulations of heat conduction are generally classified into direct heat conduction problem (DHCP) and inverse heat conduction problem (IHCP) estimation. DHCP analysis is commonly used to assess the temperature distribution within conductive media when the existing boundary conditions, thermo-physical properties of the material body, or the intensity of the heat source within it is known. IHCPs were first proposed by Stolz (1960), who also provided numerical solutions. Unlike the batch methods, sequential methods have been widely used in the prediction of parameters for time dependent problems (Beck et al., 1985; Beck, 1970; 1968). Examples are the controltheory method proposed by Zongrui and Zhongwu (1994) to estimate parameters of inverse transient heat conduction problems. Ching-China and Hong-Yung (1998) estimated unknown parameters using

\footnotetext{
* To whom correspondence should be addressed
} 
experimental data in linear systems relating to heat conduction using the Kalman filter theory and technique. The Kalman filter technique was proposed by Kalman (1960). It has been widely used in engineering, scientific, and administrative applications including inertial navigation (Grewal, 1986). It was first applied to IHPCs by Scarpa and Milano (1995) who took the estimated parameters as new variables and combined them with the state variables of original equations to form a new set of state equations. Computer programs for transient and steady-state heat conduction in two and three dimensions, and in cylindrical coordinates, have been developed. These are called HEAT2 (Blomberg, 1990; 1991), HEAT3 (Blomberg, 1993; 1994) and HEAT2R (Blomberg, 1994).

A hybrid numerical technique which combines the differential transformation and finite difference (FD) approximation (Peng and Chen, 2011) is employed to predict the laser heating problem. Blackwell (1990) used the Laplace transformation method to obtain an analytical solution for the temperature profile in a semiinfinite body with exponentially decaying (with position) heat source and convective boundary condition. Jordan (2003) constructed a nonstandard finite difference scheme to solve an initial-boundary value problem involving a quartic nonlinearity that arises in heat transfer involving conduction with thermal radiation. Lo (2011) presents a numerical approach using the hybrid differential transform finite difference method to study heat transfer in a thin film exposed to ultrashort-pulsed lasers based on the hyperbolic two-step model. The differential transformation method (Chen and Lin, 1998; Yu and Chen, 1998), a function transformation technique based on Taylor's series is applied mainly to solve the initial value problem by Lo (2011).

In the literature survey the finite difference technique is applied to solve the temperature distribution in only regular shape bodies without defects. We developed a MATLAB code considering the interpolation technique to solve plates with regular and arbitrary boundaries. The interpolation and discretization technique of the stressed structures as mentioned in the references (Ahmed et al., 2005; Deb Nath, 2002; Deb Nath et al., 2008; Ahmed and Deb Nath, 2009; Deb Nath et al., 2011; Mohiuddin et al., 2012) is used to discretize the present $2 \mathrm{D}$ heat conduction problem in the present MATLAB code. But all the practical problems are not regular in shapes. Besides, we introduce a notch and rectangular slot on the boundary and inside the heat conduction plate and obtain temperature distribution throughout the plate. In the present paper, the flow charts of our MATLAB code developed for transient heat conduction and steady state heat conduction problems are given for a better understanding of the program philosophy. To verify the soundness of the present simulation results, we solved a mixed boundary heat conduction problem analytically using the Fourier integrals (Deb Nath et al., 2006; 2007; 2007; Deb Nath and Ahmed, 2008; Deb Nath, 2008; Deb Nath and Afsar, 2009; Deb Nath and Ahmed, 2009; 2009; Deb Nath et al., 2010; Deb Nath, 2013) and the distribution of the temperature of some sections of the plate obtained by the analytical method is compared with those of the present FD method which shows good agreement with the analytical method.

\section{Theoretical formulations}

\section{1a. Finite difference form of the governing equation for the steady state heat transfer problems using the central difference technique}

The governing equation for steady two-dimensional heat conduction with constant properties and zero sources is

$$
\frac{\partial^{2} T}{\partial x^{2}}+\frac{\partial^{2} T}{\partial y^{2}}=0
$$

Using the central difference formula, we obtain

$$
\frac{\partial^{2} T(x, y)}{\partial x^{2}}=\frac{T(x+h, y)+T(x-h, y)-2 T(x, y)}{h^{2}}+O(h) .
$$


Here $h=\Delta x$ and $(i, j)$ stands for $x$ and $y$, respectively in such a way that $i+1=x+h, i-1=x-h$. The term $\mathrm{O}(h)$ indicates that the error in the omission of the term is of the order of $h$.

$$
\begin{aligned}
& \Rightarrow \frac{\partial^{2} T(i, j)}{\partial x^{2}}=\frac{T(i+1, j)+T(i-1, j)-2 T(i, j)}{h^{2}}+O(h), \\
& \frac{\partial^{2} T(x, y)}{\partial y^{2}}=\frac{T(x, y+k)+T(x, y-k)-2 T(x, y)}{k^{2}}+O(k) .
\end{aligned}
$$

Here $k=\Delta y$ and $(i, j)$ stands for $x$ and $y$, respectively in such a way that $j+1=y+k, j-1=y-k$. The term $\mathrm{O}(k)$ indicates that the error in the omission of the term is of the order of $k$.

$$
\frac{\partial^{2} T(i, j)}{\partial y^{2}}=\frac{T(i, j+l)+T(i, j-l)-2 T(i, j)}{k^{2}}+O(k) .
$$

The finite difference form of Eq.(2.1) is

$$
\frac{T(i+1, j)+T(i-1, j)-2 T(i, j)}{h^{2}}+\frac{T(i, j+l)+T(i, j-l)-2 T(i, j)}{k^{2}}=0 .
$$

Assuming finite difference mesh lengths in $x, y$ direction are same, i.e., $h=k$.

The central-difference approximation of the second derivative in space is

$$
T(i+1, j)+T(i-1, j)-4 T(i, j)+T(i, j+1)+T(i, j-1)=0 .
$$

This equation is applied at each interior grid point of the meshed structure and a set of algebraic equations is obtained after applying proper boundary conditions.

\section{1b. Finite difference form of the boundary condition of steady state heat transfer problem considering the interpolation technique}

When the finite difference mesh does not match the physical boundary of the problem, then the distribution of the temperature is obtained by four point interpolation. The details of the four point interpolation technique is given in Ahmed et al. (2005), Deb Nath (2002), Deb Nath et al. (2008), Ahmed and Deb Nath (2009), Deb Nath et al. (2011), Mohiuddin et al. (2012). The following equation is used to interpolate the temperature on the arbitrary boundary of the heat conduction problem as shown in Fig. 12

$$
\begin{aligned}
& T(i s, j a)=\frac{1}{s+t}\left[s \cdot \frac{a T(i+1, j+1)+b T(i+1, j)}{a+b}+t \frac{a T(i, j+1)+b T(i, j)}{a+b}\right] \\
& \Rightarrow T(i s, j a)=\frac{1}{h k}[\operatorname{as} T(i+1, j+1)+b s T(i+1, j)+a t T(i, j+1)+b t T(i, j)]
\end{aligned}
$$

where $T(i s, j a)$ is the temperature after interpolation using four points.

Referring to Fig.12 for top-left boundary, some actual boundary points are $P, Q, R$ and $S$. For the boundary point $P$, the reference natural field grid point is $R_{l}$. The position of $P$ with respect to $R_{l}$ is defined by $a$ and $s$ where $a$ and $s$ are the small distances in the positive $i$ and $j$ direction, respectively. For point $P$, the surrounding grid points are $R_{1}, R_{2}, R_{3}$ and $R_{4}$, whose field references are $\{i, j+1\} ;\{i, j\} ;\{i+1, j\}$ and $\{i+1$, $j+1\}$, respectively. The above equation can be used only on the reference boundary when the interpolation technique is needed; on the other hand when there is no need of the interpolation technique, the above equation is applied on the physical boundary of the problem. 


\section{Theories for transient $2 \mathrm{D}$ heat conduction}

Conservation of energy to a nodal region of volume as shown in Fig.5 considering explicit method is applied, where

$$
\dot{E}_{\text {in }}+\dot{E}_{\mathrm{g}}=\dot{E}_{\text {st }}
$$

where

$\dot{E}_{g}=0$

rate of heat entering into the region $=\dot{E}_{\text {in }}$

rate of heat generated into the region $=E_{\mathrm{g}}$

rate of heat stored in the region $=\dot{E}_{\text {st }}$

Using Fig.5 and Eq.(3.1), the transient heat conduction equation can be written as

$$
q_{a}+q_{b}+q_{c}+q_{d}=\dot{E}_{\mathrm{st}} .
$$

Using Fig.5, Eq.(3.2) can be expanded in the following form

$$
\begin{aligned}
& k A_{c} \frac{T_{i, j+1}^{p}-T_{i, j}^{p}}{\Delta y}+k A_{c} \frac{T_{i, j-1}^{p}-T_{i, j}^{p}}{\Delta y}+k A_{c} \frac{T_{i+1, j}^{p}-T_{i, j}^{p}}{\Delta x}+ \\
& +k A_{c} \frac{T_{i-1, j}^{p}-T_{i, j}^{p}}{\Delta x}=\rho C A_{c} \Delta x \frac{T_{i, j}^{p+1}-T_{i, j}^{p}}{\Delta t}
\end{aligned}
$$

let

$$
\Delta x=\Delta y .
$$

Equation (3.3) can be simplified in the following form

$$
\begin{aligned}
& \frac{k \cdot \Delta t}{\rho C(\Delta x)^{2}}\left[T_{i, j+1}^{p}+T_{i, j-1}^{p}+T_{i+1, j}^{p}+T_{i-1, j}^{p}-4 T_{i, j}^{p}\right]=T_{i, j}^{p+1}-T_{i, j}^{p}, \\
& F\left[T_{i, j+1}^{p}+T_{i, j-1}^{p}+T_{i+1, j}^{p}+T_{i-1, j}^{p}-4 T_{i, j}^{p}\right]=T_{i, j}^{p+1}-T_{i, j}^{p} .
\end{aligned}
$$

Using Fig.5 and Eq.(3.5), the final form of the transient heat conduction equation is as follows

$$
\begin{aligned}
& T_{i, j}^{p+1}=T_{i, j}^{p}\left(1-4 F_{0}\right)+F_{0}\left[T_{i+1, j}^{p}+T_{i-1, j}^{p}+T_{i, j+1}^{p}+T_{i, j-1}^{p}\right], \\
& F_{0}=\frac{k \Delta t}{\rho C(\Delta x)^{2}},
\end{aligned}
$$

$k$ is thermal conductivity, $\rho$ is the density of a material, $C$ is the specific heat capacity, $\Delta t$ is the time step in second, $\Delta x$ is the mesh length in the $x$ direction, $\Delta y$ is the mesh length in the $y$ direction, $A_{c}$ is the cross 
sectional area of the plate. $q_{a}$ is the rate of heat flow in the $\mathrm{AE}$ direction, $q_{b}$ is the rate of heat flow in the $\mathrm{BE}$ direction, $q_{c}$ is the rate of heat flow in the DE direction, $q_{d}$ is the rate of heat flow in the CE direction as shown in Fig.5.

To solve the transient phenomena in a $2 \mathrm{D}$ heat conduction plate, the plate is discretized into grids. At the boundary grids, the real boundary temperature of the plate is applied. Inside the plate the above Eq.(3.6) is applied at all grids except the boundary grids of the plate. The initial temperature at all internal grid points of the plate is are considered to be $30^{\circ} \mathrm{C}$. Using boundary temperatures, initial temperatures at all internal grids and applying the above Eq.(3.6) in all internal grid points of the plate, the temperature at all grids is updated with time till the temperature of all grids reaches the equilibrium temperature.

\section{Analytic solution of a mixed boundary heat conduction problem}

The governing equation of the $2 \mathrm{D}$ conduction heat transfer is

$$
\frac{\partial^{2} T}{\partial x^{2}}+\frac{\partial^{2} T}{\partial y^{2}}=0
$$

To solve the problem shown in Fig.9 satisfying the boundary conditions mentioned in Tab.1 analytically, we assume

$$
\begin{aligned}
& T=Y_{m} \sin \alpha x, \\
& \frac{\partial T}{\partial x}=Y_{m} \cdot \alpha \cdot \cos \alpha x, \\
& \frac{\partial^{2} T}{\partial x^{2}}=-Y_{m} \cdot \alpha^{2} \cdot \sin \alpha x, \\
& \frac{\partial T}{\partial y}=Y_{m}^{\prime} \cdot \alpha \cdot \sin \alpha x, \\
& \frac{\partial^{2} T}{\partial y^{2}}=Y_{m}^{\prime \prime} \cdot \sin \alpha x .
\end{aligned}
$$

Combining Eqs (4.1), (4.2b) and (4.2d), we obtain the following relationship

$$
\begin{aligned}
& -Y_{m} \cdot \alpha^{2} \sin \alpha x+Y_{m}^{\prime \prime} \sin \alpha x=0, \\
& -Y_{m} \cdot \alpha^{2}+Y_{m}^{\prime \prime}=0 .
\end{aligned}
$$

Let us assume

$$
\begin{aligned}
& Y_{m}=e^{m y}, \\
& Y_{m}^{\prime}=m \cdot e^{m y}, \\
& Y_{m}^{\prime \prime}=m^{2} \cdot e^{m y} .
\end{aligned}
$$

Combining Eqs (4.3), (4.4) and (4.4b), we obtain 


$$
\begin{aligned}
& m^{2} \cdot e^{m y}-\alpha^{2} \cdot e^{m y}=0, \\
& m^{2}-\alpha^{2}=0, \\
& m= \pm \alpha .
\end{aligned}
$$

The general solution of the Eq.(4.3) is

$$
Y_{m}=A e^{\alpha y}+B e^{-\alpha y} .
$$

Combining Eqs (4.2) and (4.7) we obtain the following relation which express the temperature distribution throughout the plate

$$
T=\left(A e^{\alpha y}+B e^{-\alpha y}\right) \sin \alpha x .
$$

The above Eq.(4.8) can be used to solve the problem as shown in Fig.9 (Deb Nath et al., 2006; 2007; 2007; Deb Nath and Ahmed, 2008; Deb Nath, 2008; Deb Nath and Afsar, 2009; Deb Nath and Ahmed, 2009; 2009; Deb Nath et al., 2010; Deb Nath, 2013)

$$
\begin{aligned}
& T=\left(A e^{\alpha y}+B e^{-\alpha y}\right) \sin \alpha x=E_{0}+E_{m} \sin \alpha x, \\
& E=0 \\
& E_{m}=\frac{2}{a} \int_{0}^{a} T_{0} \sin \alpha x=\frac{4 T_{0}}{m \pi} \text { where } m=1, \quad 3, \quad 5 \ldots \ldots \infty
\end{aligned}
$$

when

$$
\begin{aligned}
& y=0, \quad T=T_{0}=1000^{\circ} \mathrm{C}, \\
& A+B=E_{m},
\end{aligned}
$$

when

$$
\begin{aligned}
& y=b, \quad T=T_{0}=1000^{\circ} \mathrm{C}, \\
& A \cdot e^{\alpha b}+B \cdot e^{-\alpha b}=E_{m}, \\
& A=\frac{E_{m}\left(1-e^{\alpha b}\right)}{e^{-\alpha b}-e^{\alpha b}}, \\
& B=E_{m}-\frac{E_{m}\left(1-e^{\alpha b}\right)}{e^{-\alpha b}-e^{\alpha b}} .
\end{aligned}
$$

After substituting $A$ and $B$ in the above Eq.(4.8), we obtain the distribution of temperature throughout the plate.

\section{Results and discussion}

The distribution of temperature of a plate having mixed boundary conditions can be solved using analytical and numerical methods. Although the analytical method gives accurate result, only few simple problems can be solved analytically, whereas complex practical problems cannot be solved analytically. So 
an alternative approach to solve complex practical heat conduction problems is numerical. Among the numerical approaches, finite element and finite difference methods are most popular. The finite element method is widely used to solve the heat conduction problem because the finite difference method is sometimes unable to deal with the problems with complex boundary conditions. If the boundary conditions of the heat conduction problem are satisfied accurately by the finite difference method, it gives accurate results like the analytical approach. Here we study different types of practical and complex heat conduction problems by the finite difference method using our MATLAB code applying the algorithm mentioned in flowcharts 1 and 2. Before analyzing some heat conduction problems, we have solved a simple mixed boundary heat conduction problem analytically as well as by the finite difference method and we compare the distribution of temperature at some sections of the plate obtained by the analytical approach to that of some sections of the plate obtained by the finite difference method. In the present analysis, we show the temperature distribution in different practical problems. Figure 1 shows a simple $2 \mathrm{D}$ heat conduction plate problem in which the temperature of top side of the plate is $100^{\circ} \mathrm{C}$ and on the bottom side, it is $0^{\circ} \mathrm{C}$. The temperature of the left and right side of the plate is $30^{\circ} \mathrm{C}$. The length and width of the plate are 10 unit. To solve the problem using the finite difference technique, the plate is discretized in different mesh sizes. The four different mesh sizes are taken into account in the present study $(h=0.5, k=0.5 ; h=0.25, k=0.25 ; h=$ $0.2, k=0.2$ and $h=0.125, k=0.125$ ) and in every case mesh lengths in $x$ and $y$ directions are assumed same. Effects of mesh length on the temperature distribution at sections $x=8$ and $y=8$ of the plate as shown in Fig. 1 are illustrated in Figs 2 and 3. From Figs 2 and 3 it is clearly observed that there is a negligible effect of mesh length on the temperature distribution of the plate. For this reason, we choose the mesh length $h=$ 0.5 and $k=0.5$ for the discretization of all other problems which are studied here. Figure 4 illustrates the contour plot of the temperature distribution throughout the plate as observed in Fig. 1 and from the contour plot, we can understand the temperature distribution at any section of the plate roughly which shows the same temperature. From Fig.4, it is observed that two different temperature profiles generate inside the plate as shown in Fig.1. Figure 6 shows a mixed boundary heat conduction plate problem in which the temperature of the top boundary is $1000^{\circ} \mathrm{C}$ and the temperature of the bottom boundary is $30^{\circ} \mathrm{C}$ and the temperature of the left and right boundary is $30^{\circ} \mathrm{C}$. Using this problem as shown in Fig.6, the transient heat conduction phenomenon is solved using Eq.(3.6) and flow chart 1. Figures 7 and 8 show the distribution of temperature at the sections $y=10$ and $x=10$ of the plate as a function of $x$ and $y$ respectively with time. With the increase of time temperature increases and after a certain time, temperature does not increase, i.e., the system reaches equilibrium temperature. The shape of the distribution of temperature at each interval of time is similar. To verify the soundness of the present analysis of the temperature distribution of $2 \mathrm{D}$ heat conduction problems, we have solved the problem as shown in Fig. 9 with the boundary conditions mentioned in Tab.1 analytically using Fourier integrals (Deb Nath et al., 2006; 2007; 2007; Deb Nath and Ahmed, 2008; Deb Nath, 2008; Deb Nath and Afsar, 2009; Deb Nath and Ahmed, 2009; 2009; Deb Nath et al., 2010; Deb Nath, 2013). The same problem is also solved using the finite difference technique by our code using the flowchart 2 . Figure 10 shows a comparative study of the distribution of temperature at some sections of the plate obtained by the analytical method to that obtained by the finite difference method. The present temperature distribution at some sections such as $y / a=0,0.25$ and 0.5 of the plate obtained by the finite difference method totally coincides with the temperature of those sections of the plate obtained by the analytical method. From the comparative study it is clear that the present solution of different problems using the finite difference technique is as accurate as the analytical approach. The rectangular plate with its aspect ratio 2 (the ratio of the dimension of the plate in $x$ and $y$ directions) as shown in Fig. 11 is solved considering steady state heat transfer using the finite difference technique and the flowchart 2. Using the interpolation technique based on Eq.(2.3) as shown in Fig.12, the same problem is solved when one of the boundaries of the plate does not pass through the grids of the domain as shown in Fig.11. Figure 13 shows the contour plot of the distribution of temperature of the plate as shown in Fig. 11 by the finite difference technique using the steady state heat conduction concept. From Fig.13, it is observed that the temperature distribution of the boundary is equal to the applied boundary conditions which ensures the reliability of the solutions. The same problem as shown in Fig. 1 is extended introducing a notch on the top side of the plate and hot fluid with temperature $100^{\circ} \mathrm{C}$ is passed through this notch as shown in Fig.14. Except the notch the temperature of the top boundary of the 
plate is $0^{\circ} \mathrm{C}$ and the temperature of the left and right side boundary of the plate is $0^{\circ} \mathrm{C}$. The temperature of the bottom boundary of the plate is $20^{\circ} \mathrm{C}$. Figure 15 shows the distribution of temperature of the plate as shown in Fig. 14 which satisfies the physical temperature boundary conditions of the plate and inside the plate two different temperature profiles are observed. At left and right portions of the plate two symmetric temperature distributions are observed. Along the middle portion of the plate, another type of temperature profile is observed. From the top side of the plate the temperature decreases towards the bottom side of the plate.

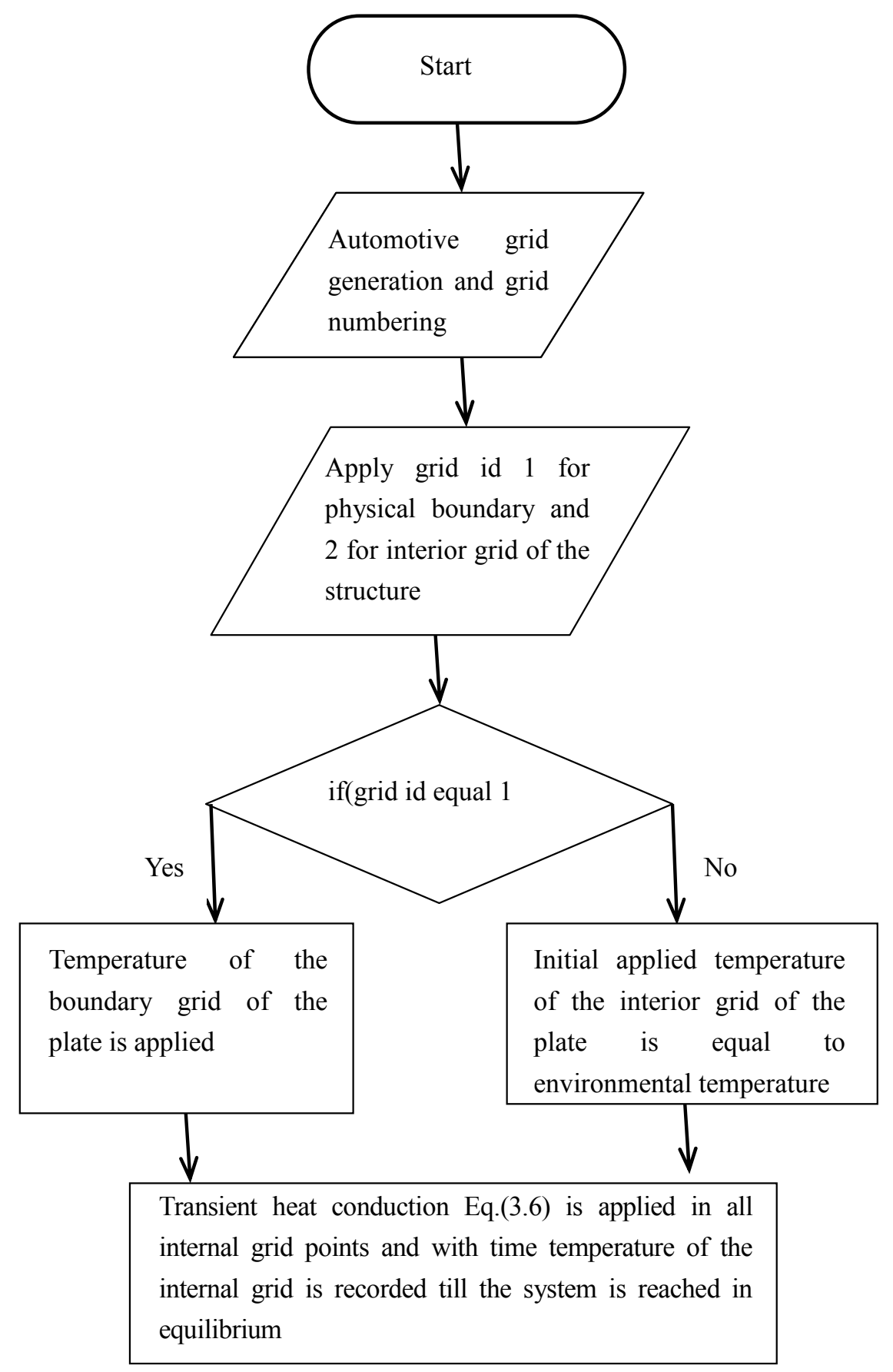

Flowchart 1. Flow chart of different steps to determine the temperature profile of 2-D transient heat conduction problem in our developed MATLAB code 1. 


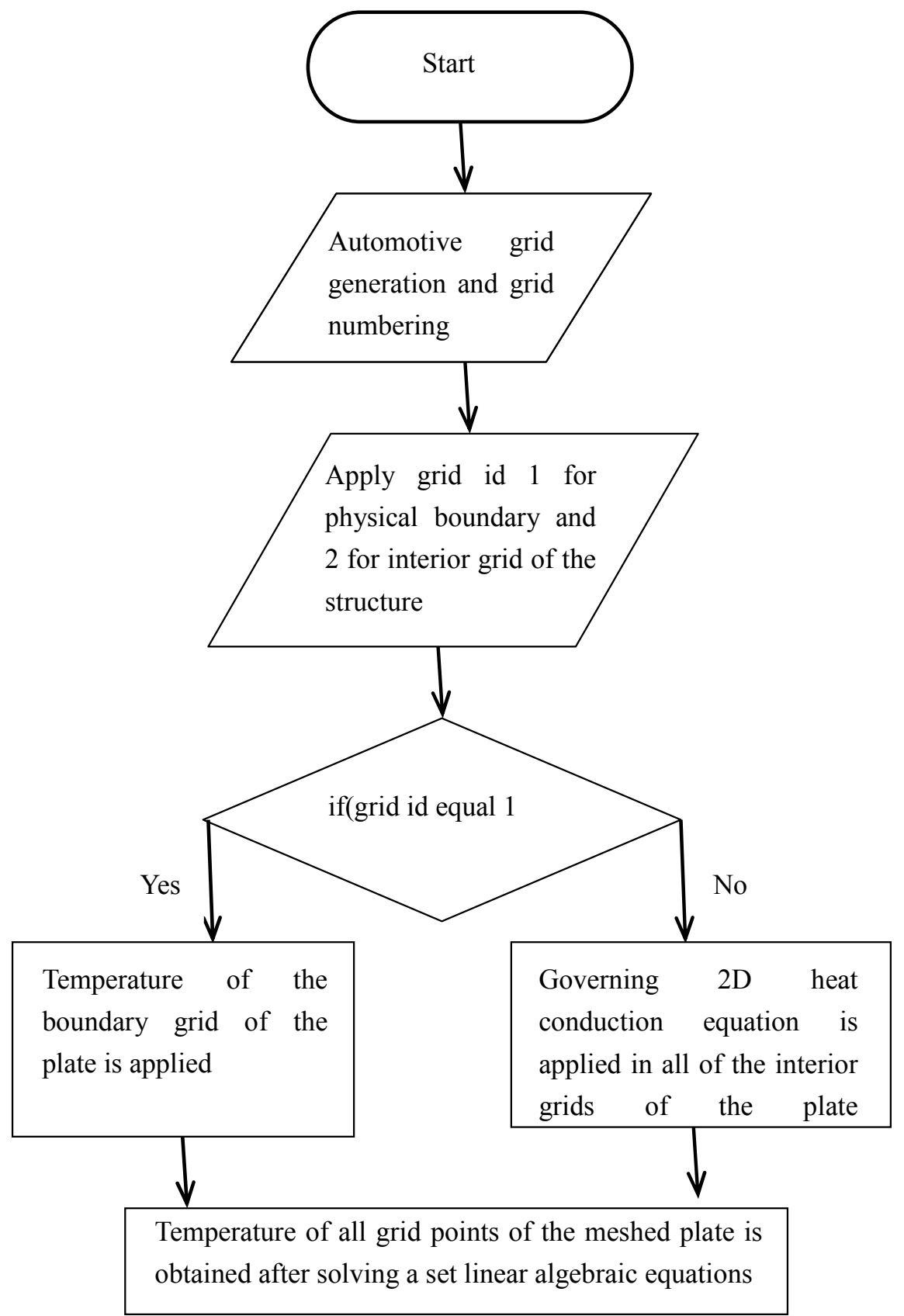

Flow chart 2. Flow chart of different steps to determine the temperature profile of 2-D steady state heat conduction problem in our developed MATLAB code 2. 


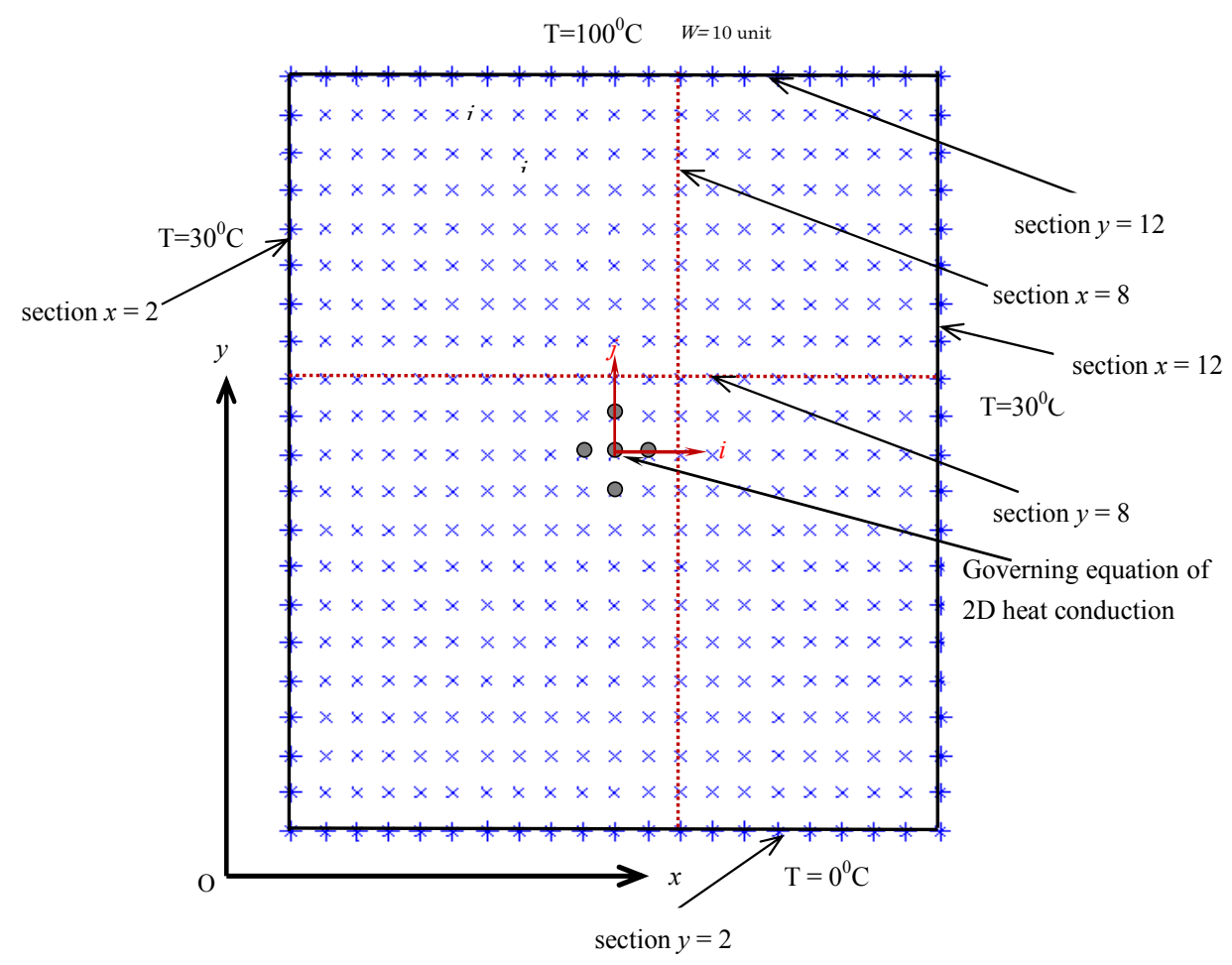

Fig.1. Application of the governing equation of 2D heat conduction of a rectangular plate at different temperatures.

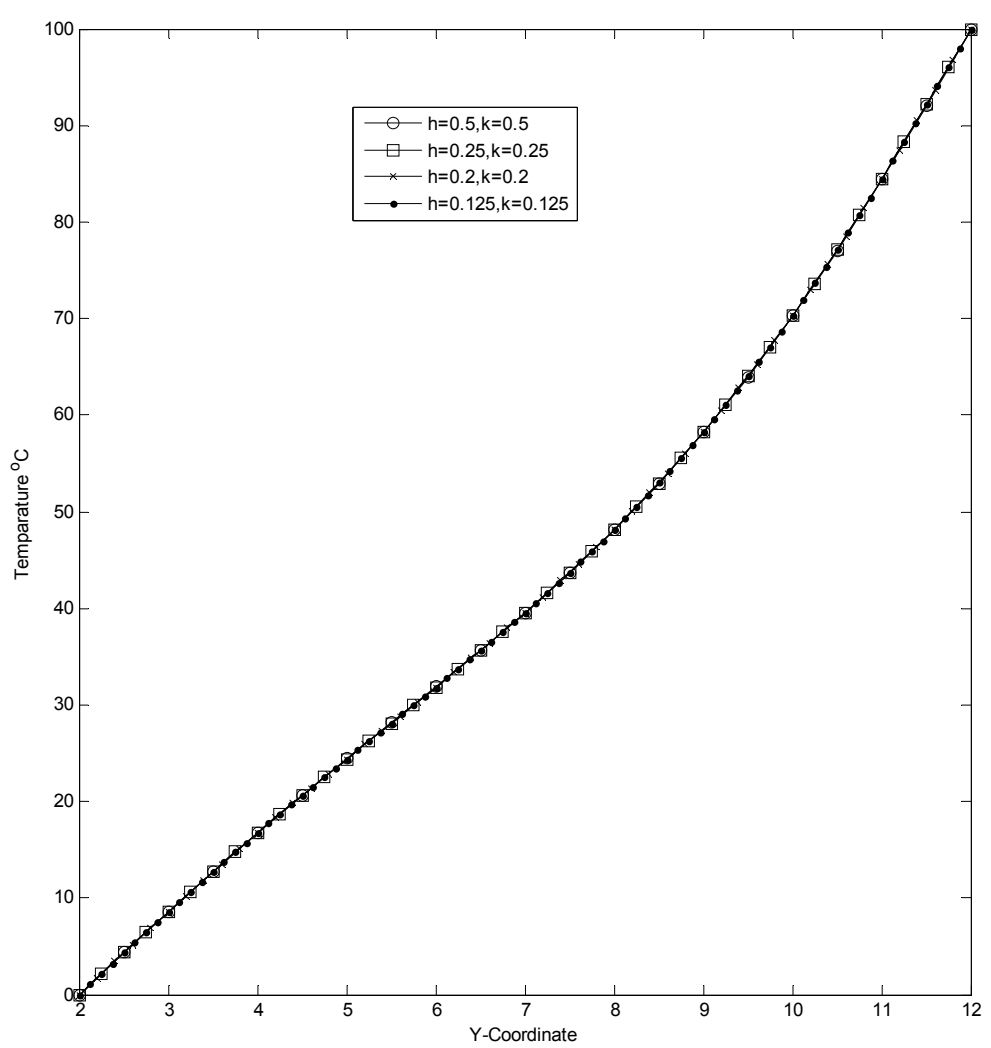

Fig.2. Effects of mesh size on the temperature distribution as a function of $y$ coordinate of a rectangular plate at the section, $x=8$ unit as shown in Fig.1. 


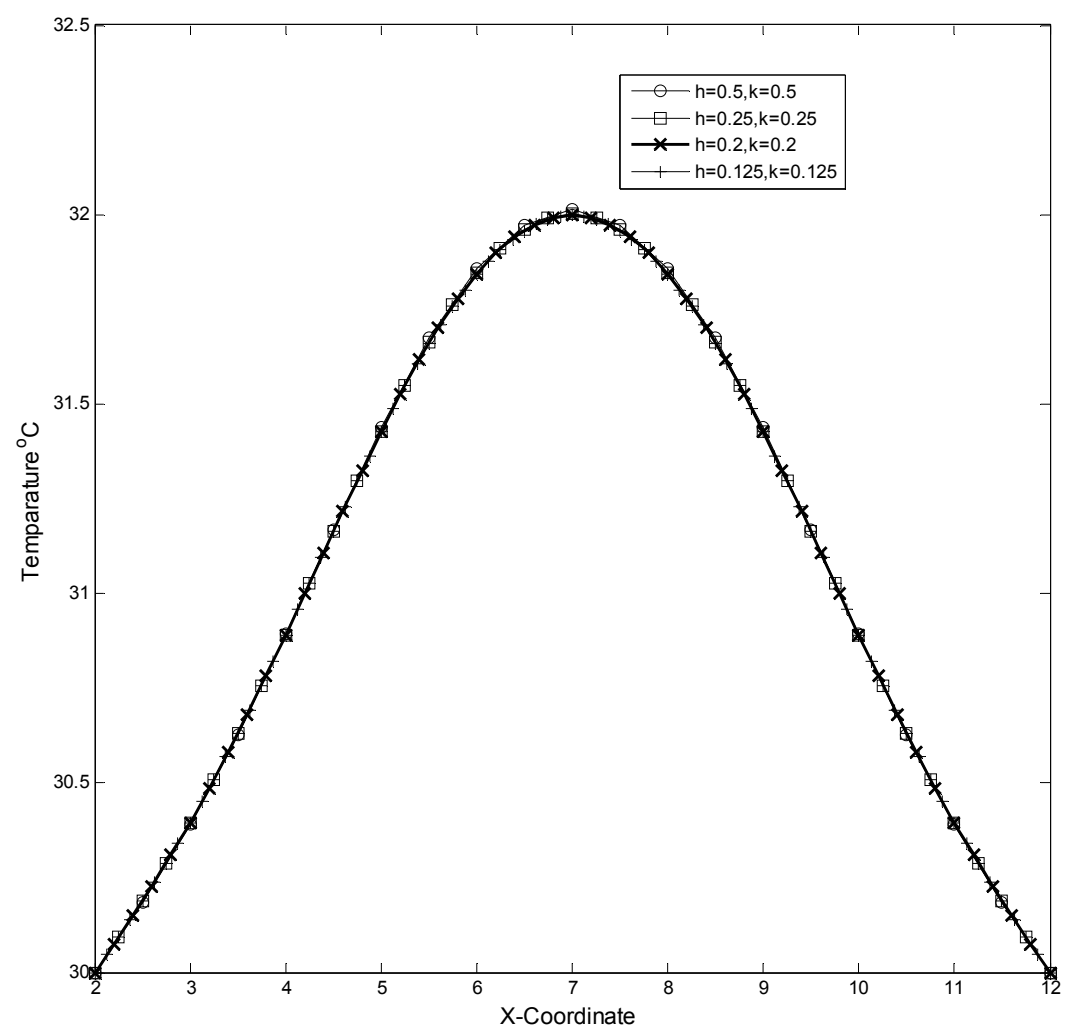

Fig.3. Effects of mesh size on the temperature distribution as a function of $x$ coordinate of a rectangular plate at the section, $y=8$ unit as shown in Fig.1.

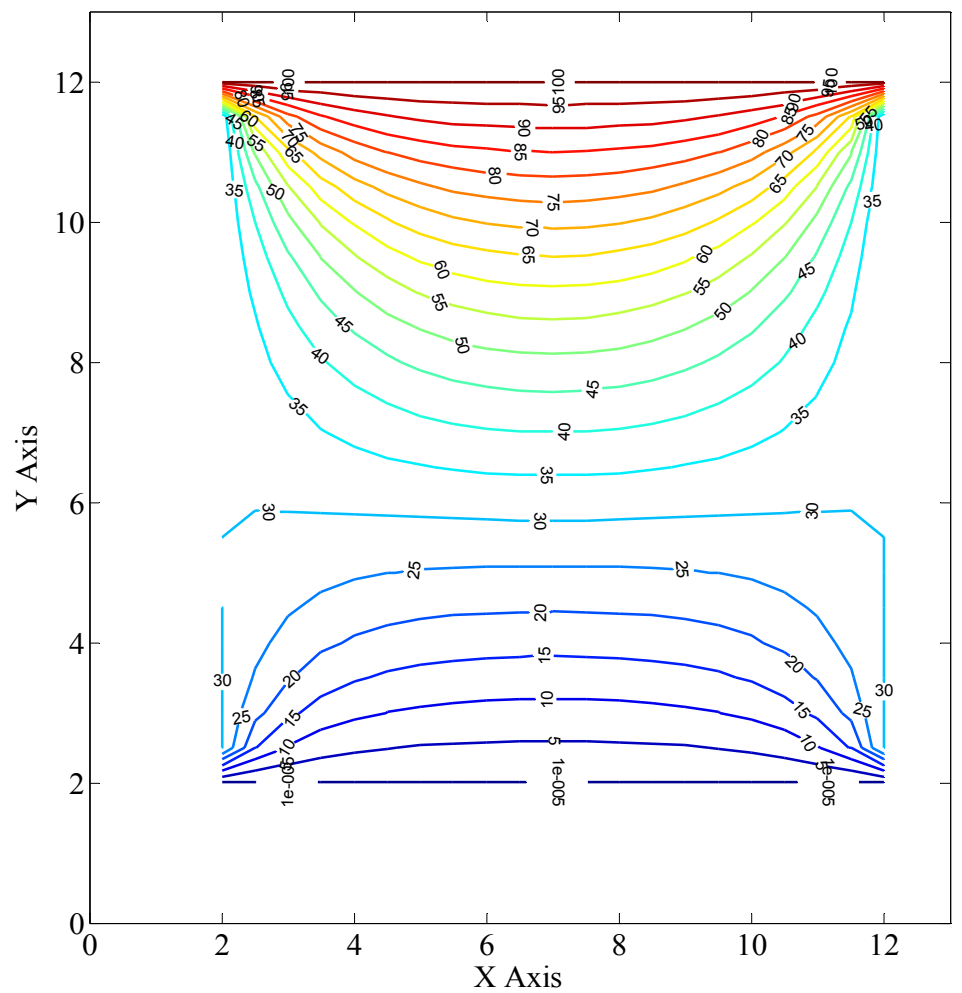

Fig.4. Contour plot of the distribution of temperature throughout the plate according to the problem mentioned in Fig.1. 


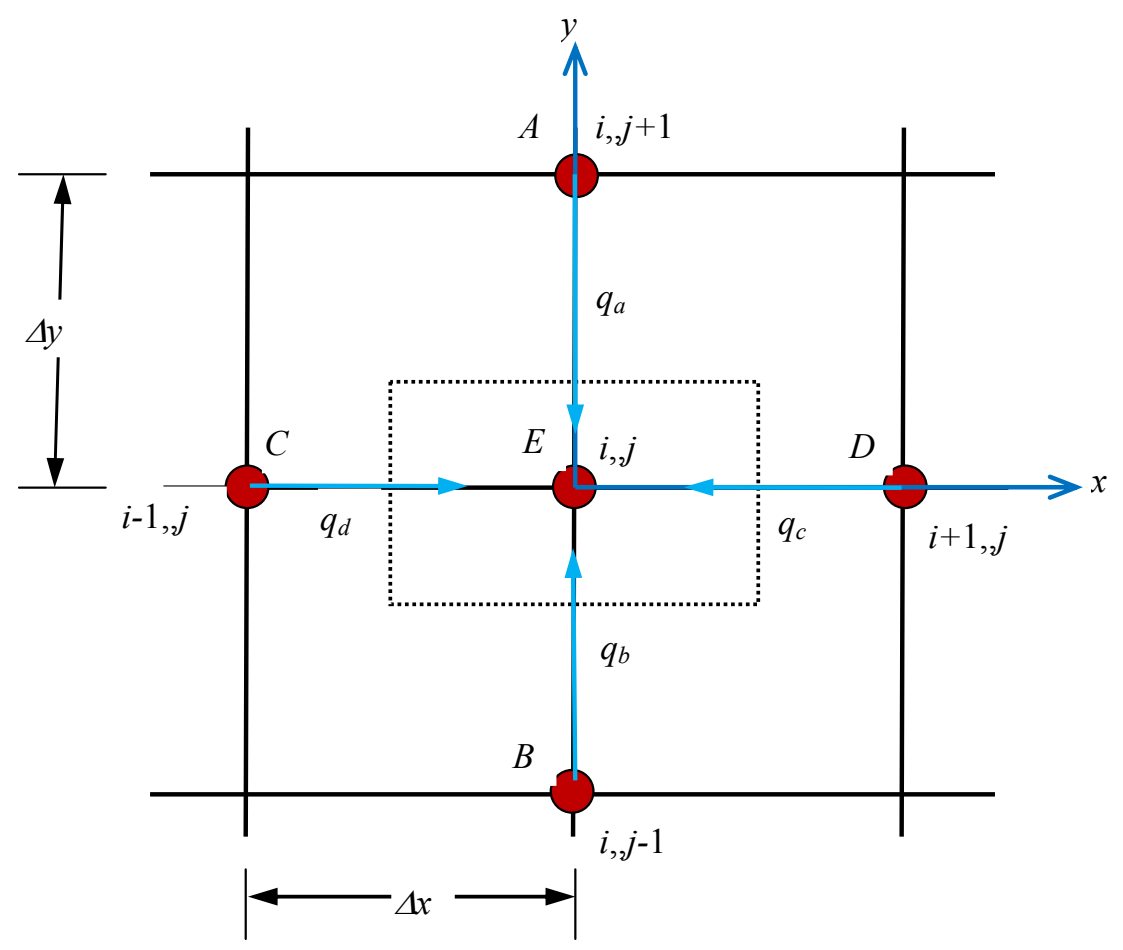

Fig.5. Explicit method to solve the transient heat transfer phenomenon using the mentioned meshes.

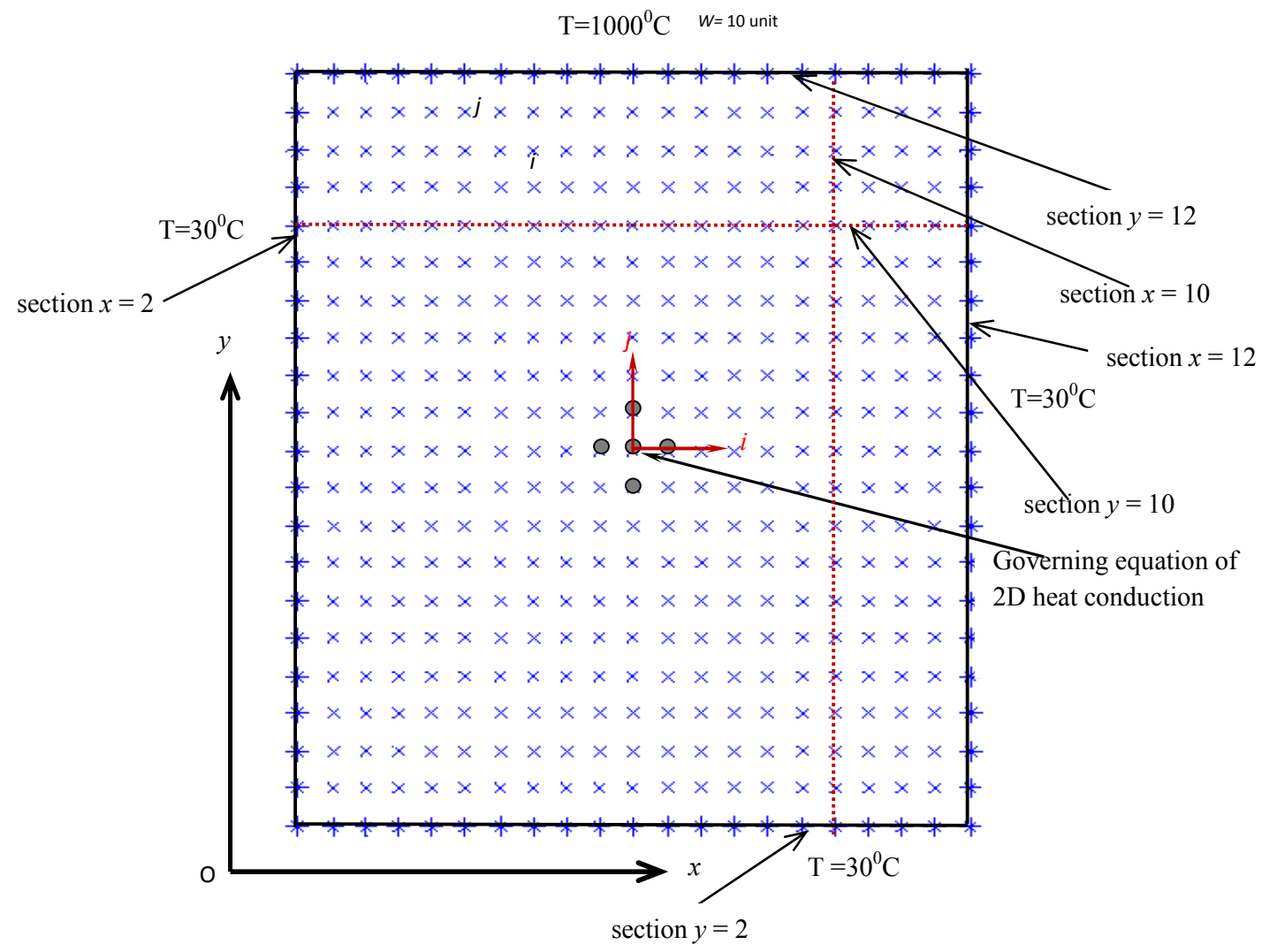

Fig.6. Application of the transient heat conduction phenomenon of a rectangular plate with its boundaries at different temperatures. 


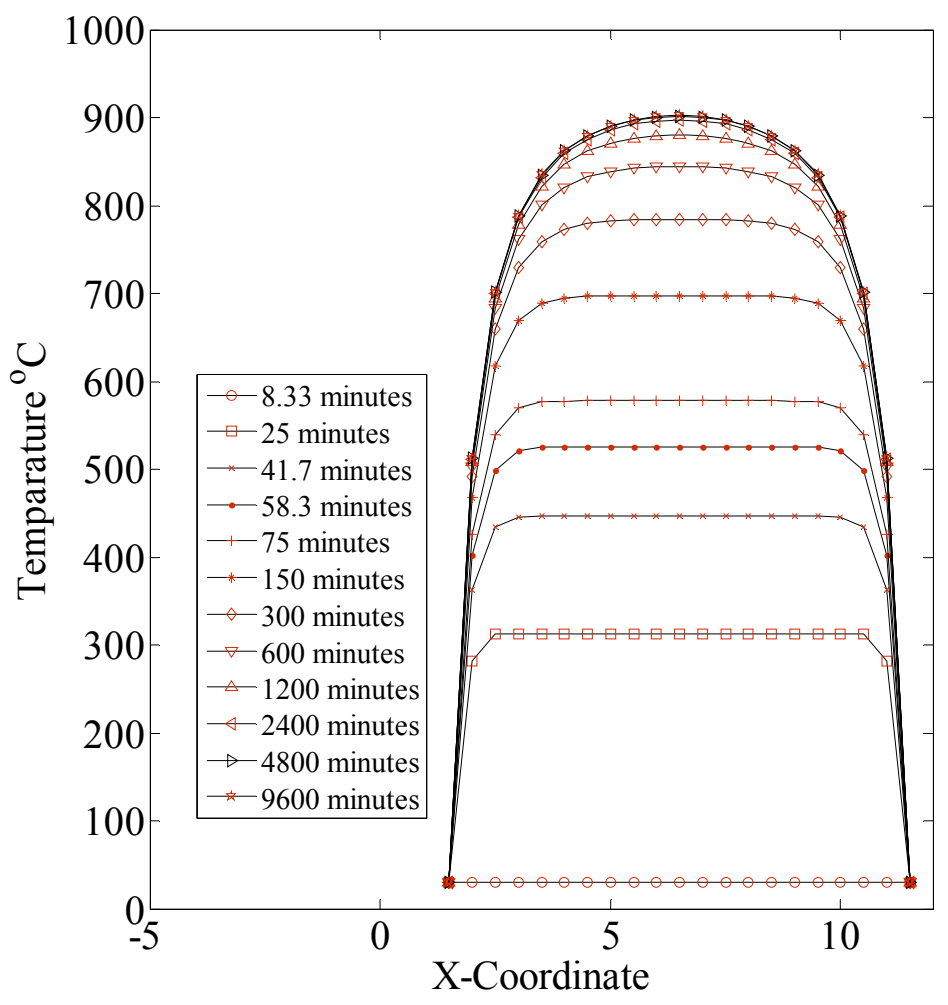

Fig.7. Distribution of temperature at the section $y=10$ unit considering the transient heat conduction phenomenon as shown in the problem given in Fig.6.

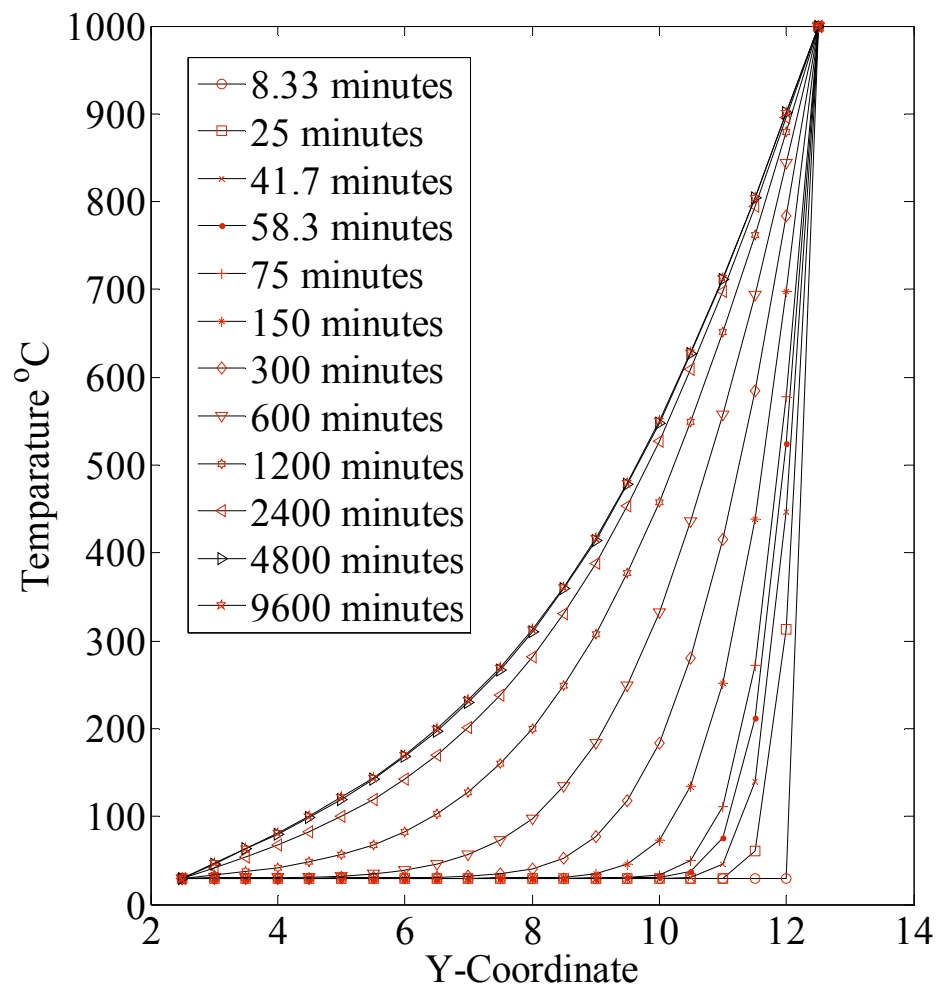

Fig.8. Distribution of temperature at the section $x=10$ unit considering the transient heat conduction phenomenon as shown in the problem given in Fig. 6. 


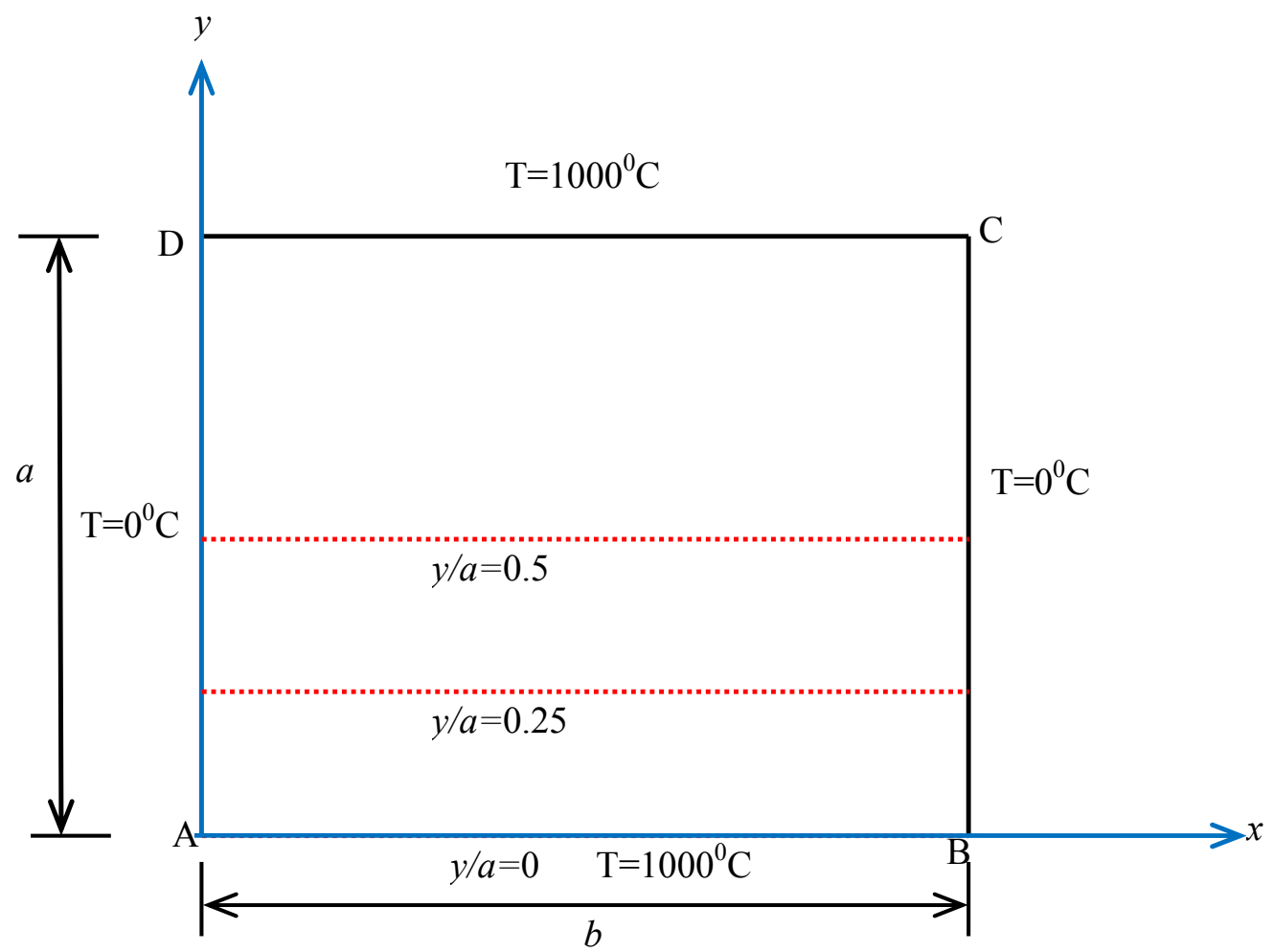

Fig.9. A square thin aluminum plate with different thermal boundary conditions.

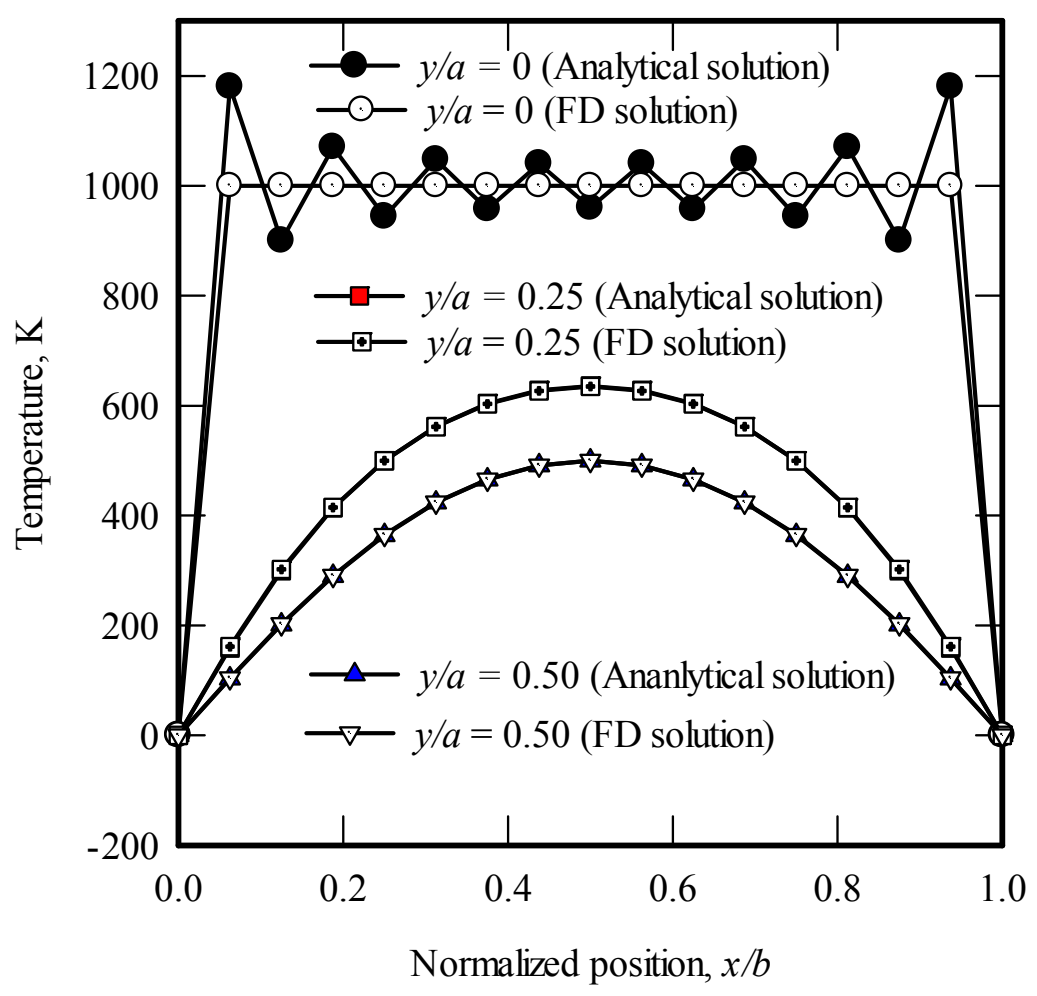

Fig.10. Comparative study of the distribution of temperature at different sections of the plate as shown in Fig. 9 by FD and analytical approach. 


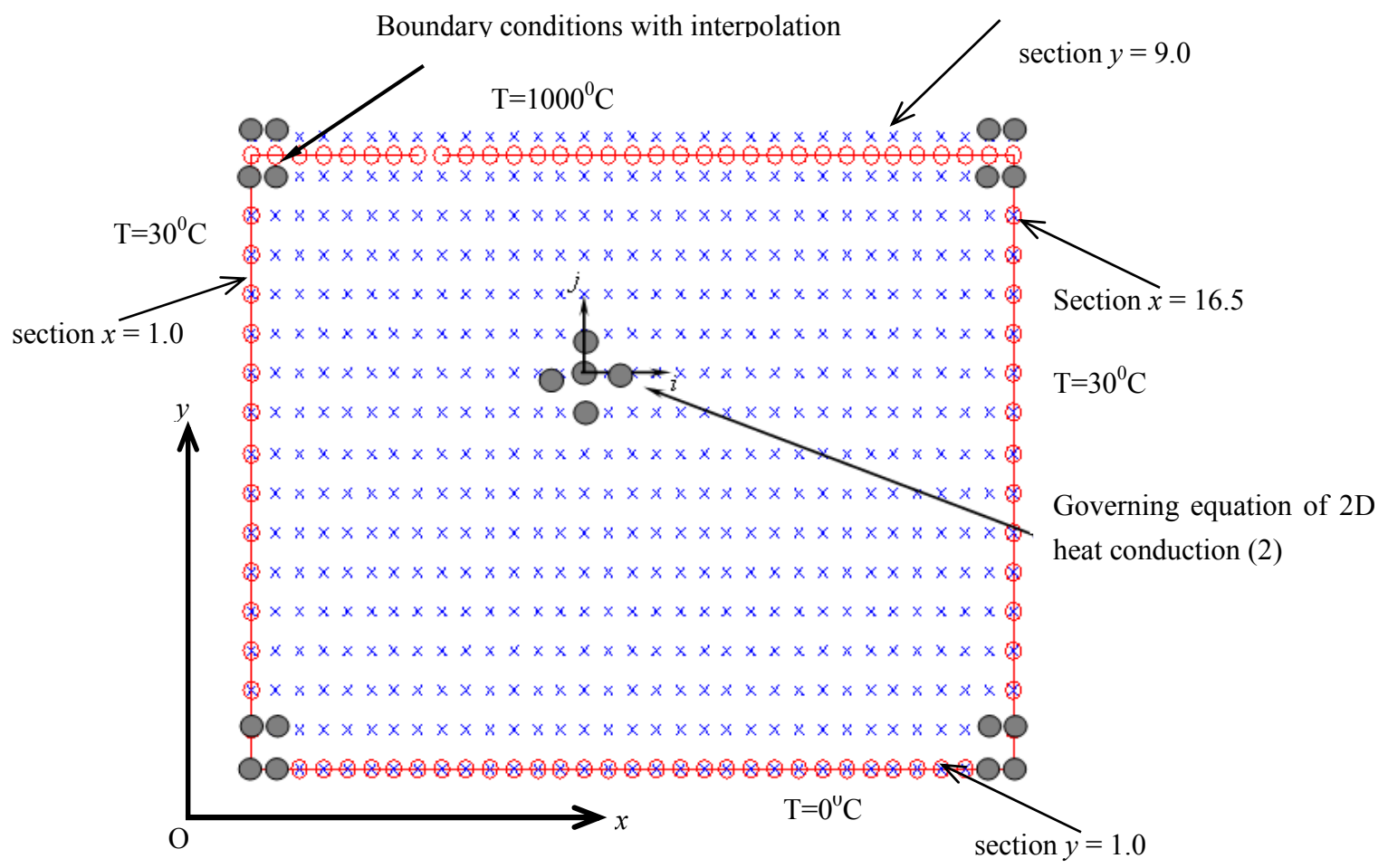

Fig.11. Application of the governing equation of 2D heat conduction and boundary conditions using the interpolation technique of a rectangular plate at different temperatures.

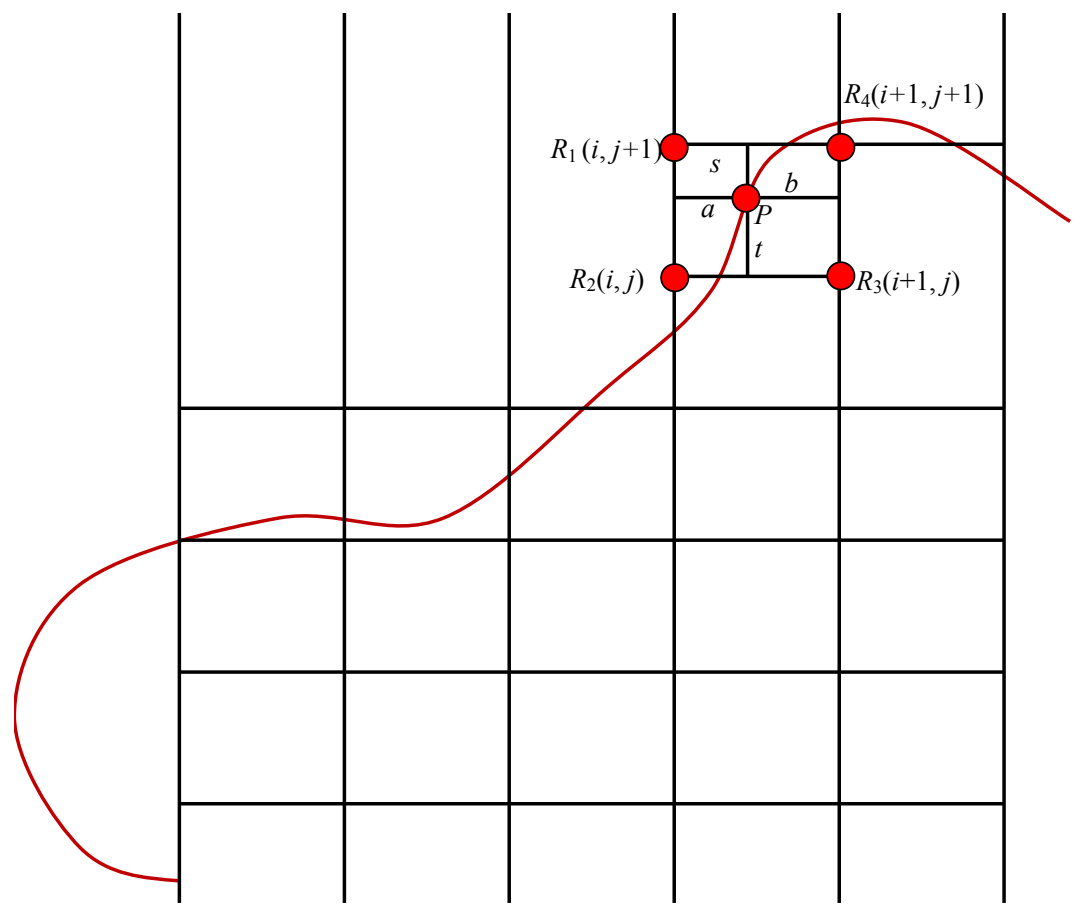

Fig.12. Locators $a, b, s$ and $t$ of the boundary point $P$ with respect to its reference point $R_{1}, R_{2}, R_{3}$, and $R_{4}$. 


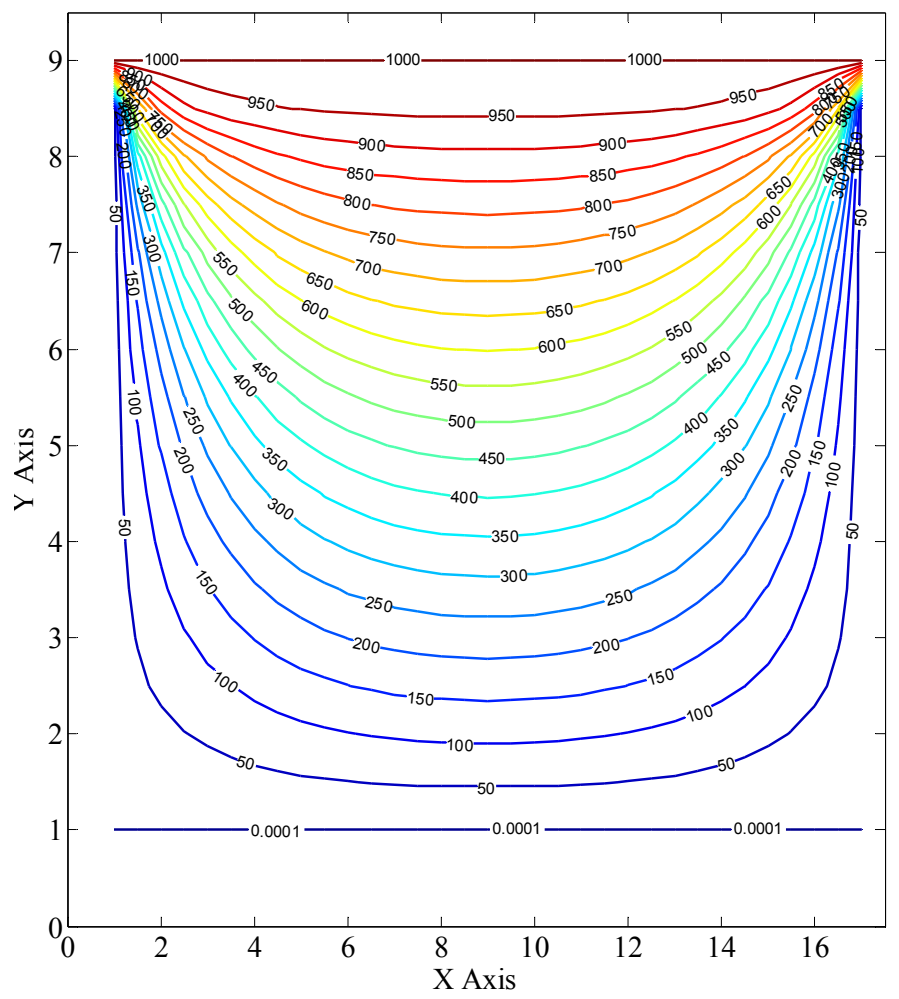

Fig.13. Contour plot of the distribution of temperature throughout the plate according to the problem mentioned in Fig. 11 using the interpolation technique on the top boundary.

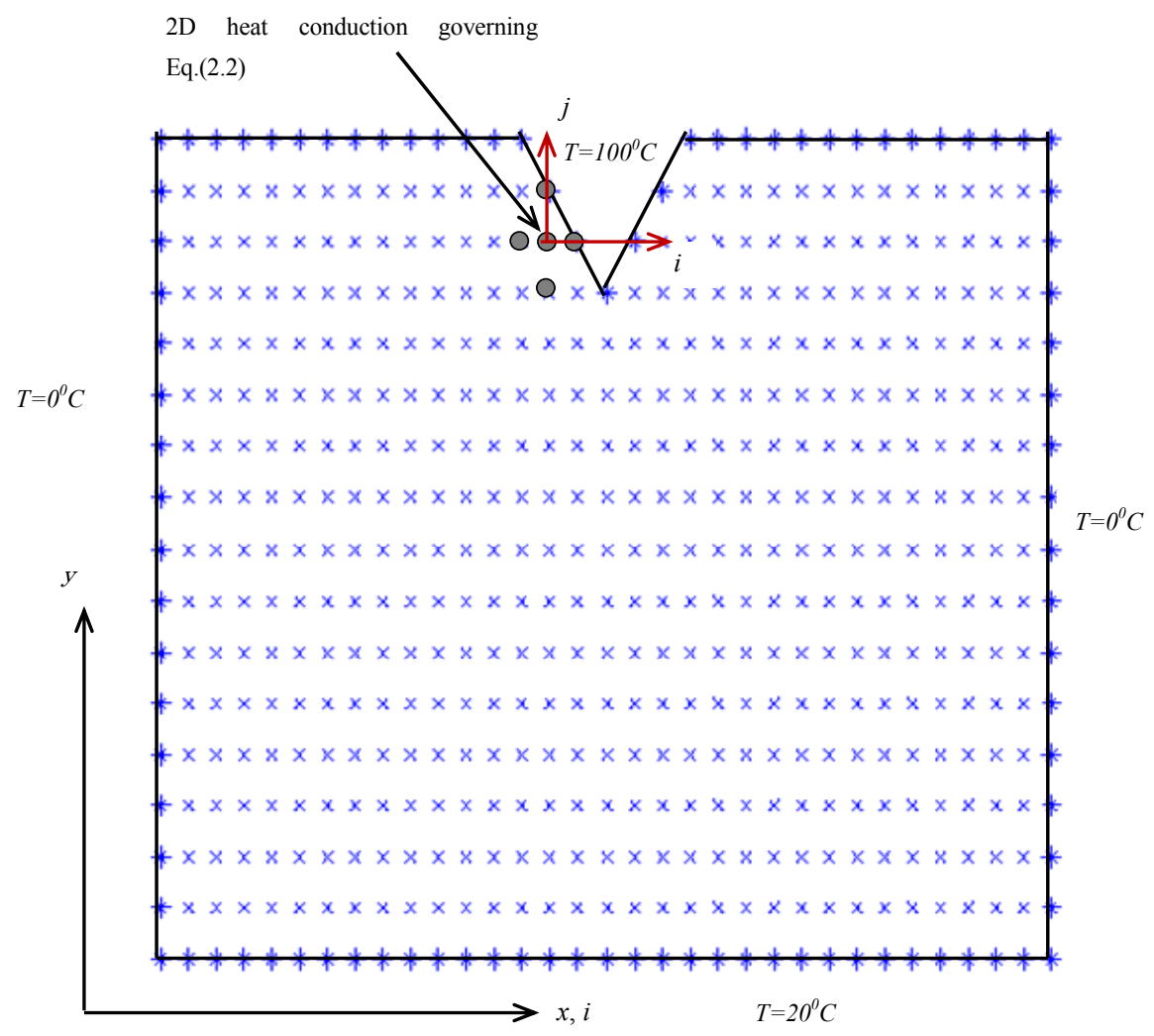

Fig.14. Application of the governing equation of 2D heat conduction and boundary conditions with different temperatures of a rectangular plate having a notch. 


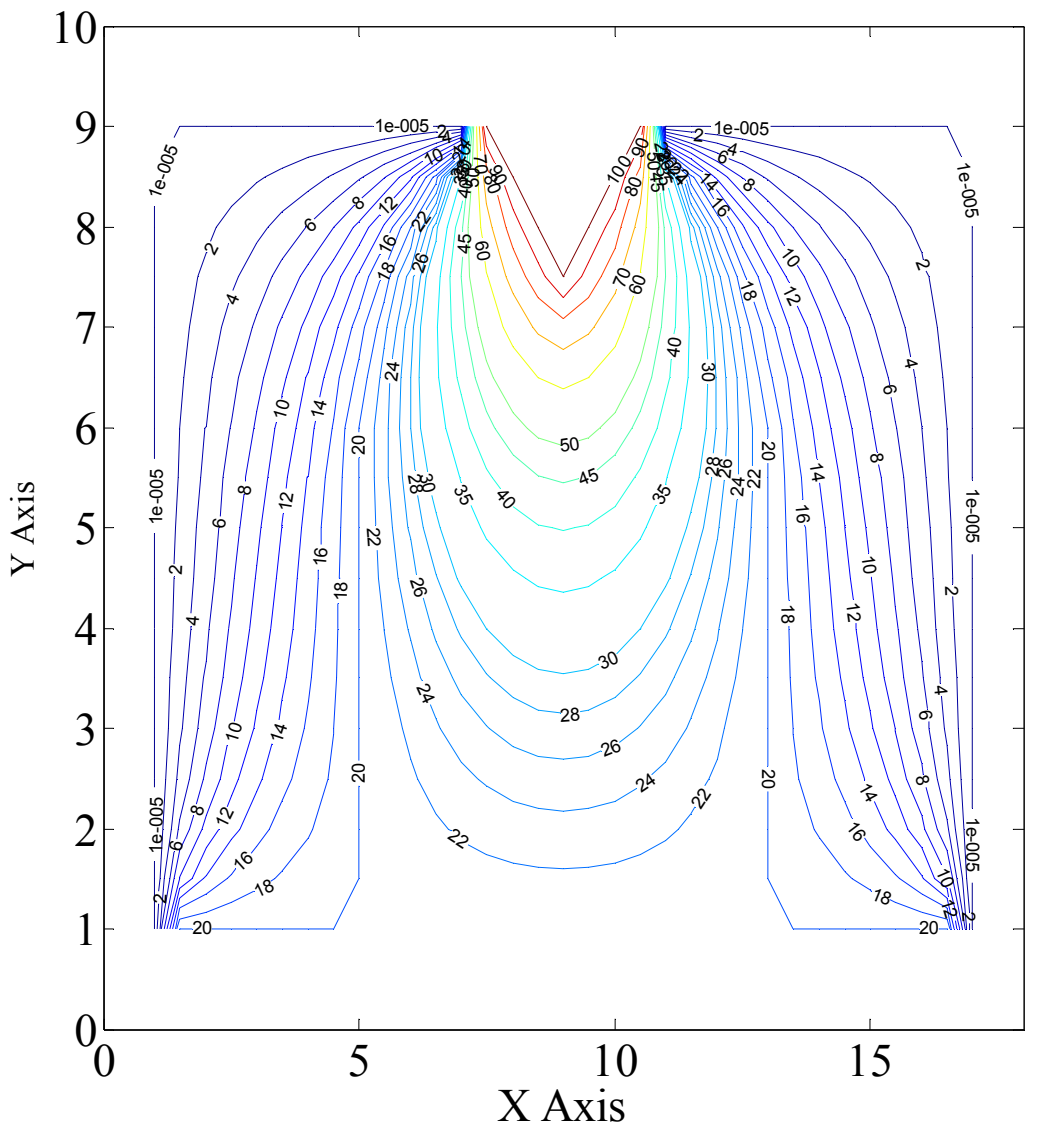

Fig.15. Contour plot of the distribution of temperature throughout the plate according to the problem mentioned in Fig.14.

Table 1. Boundary conditions of the 2D heat conduction problem as shown in Fig.9.

\begin{tabular}{|c|c|l|}
\hline \multirow{4}{*}{$\begin{array}{c}\text { Temperature at the } \\
\text { boundary of the plate }\end{array}$} & $\mathrm{AB}$ & $1000^{\circ} \mathrm{C}$ \\
\cline { 2 - 3 } & $\mathrm{CD}$ & $1000^{\circ} \mathrm{C}$ \\
\cline { 2 - 3 } & $\mathrm{AD}$ & $0^{\circ} \mathrm{C}$ \\
\hline \multirow{4}{*}{$\begin{array}{c}\text { Temperature of the } \\
\text { corner points of the } \\
\text { plate }\end{array}$} & $\mathrm{BC}$ & $0^{\circ} \mathrm{C}$ \\
\cline { 2 - 3 } & $\mathrm{A}$ & $T_{A}=0^{\circ} \mathrm{C}$ \\
\cline { 2 - 3 } & $\mathrm{B}$ & $T_{B}=0^{\circ} \mathrm{C}$ \\
\cline { 2 - 3 } & $\mathrm{C}$ & $T_{C}=0^{\circ} \mathrm{C}$ \\
\hline
\end{tabular}

The problem defined in Fig.14 is extended including a slot inside the plate and a hot fluid having temperature $1000^{\circ} \mathrm{C}$ is passed through this rectangular slot and a hot fluid having temperature $100^{\circ} \mathrm{C}$ is passed through the triangular channel and the rest of the boundaries of the plate, the temperature is maintained at $30^{\circ} \mathrm{C}$ as shown in Fig.16. Figure 17 describes the temperature distribution of the plate according to the defined problem as shown in Fig.16. Away from the rectangular slots, the temperature gradually decreases and is equal to the applied temperature on the boundaries when it approached the 
boundary. A rectangular plate having three slots is meshed in which a hot fluid having temperature $1000^{\circ} \mathrm{C}$ is passed through the middle slot and cold fluid having temperature $0^{\circ} \mathrm{C}$ is passed through the rest of other two slots as shown in Fig.18. The distribution of temperature of the problem defined in Fig.18 is shown in Fig.19. Three different symmetric temperature distributions are observed in the plate. Between the hot and cold zones, the temperature changes abruptly. A rectangular plate having three slots is meshed in which a cold fluid having temperature $0^{\circ} \mathrm{C}$ is passed through the middle slot and a hot fluid having temperature $1000^{\circ} \mathrm{C}$ is passed through the rest of other two slots as shown in Fig.20. The distribution of temperature of the problem defined in Fig.20 is shown in Fig.21. Two different symmetric temperature distributions are observed in the plate. Between the hot and cold zone, the temperature changes abruptly. Using the transient phenomenon, the time required to reach the steady state temperature is obtained for the present problem as shown in Fig. 6 considering different materials which are shown in Table 2. From Table 2, it is observed that the plates made of silver and stainless steel take the lowest time and the longest time, respectively, to reach the steady state temperature.

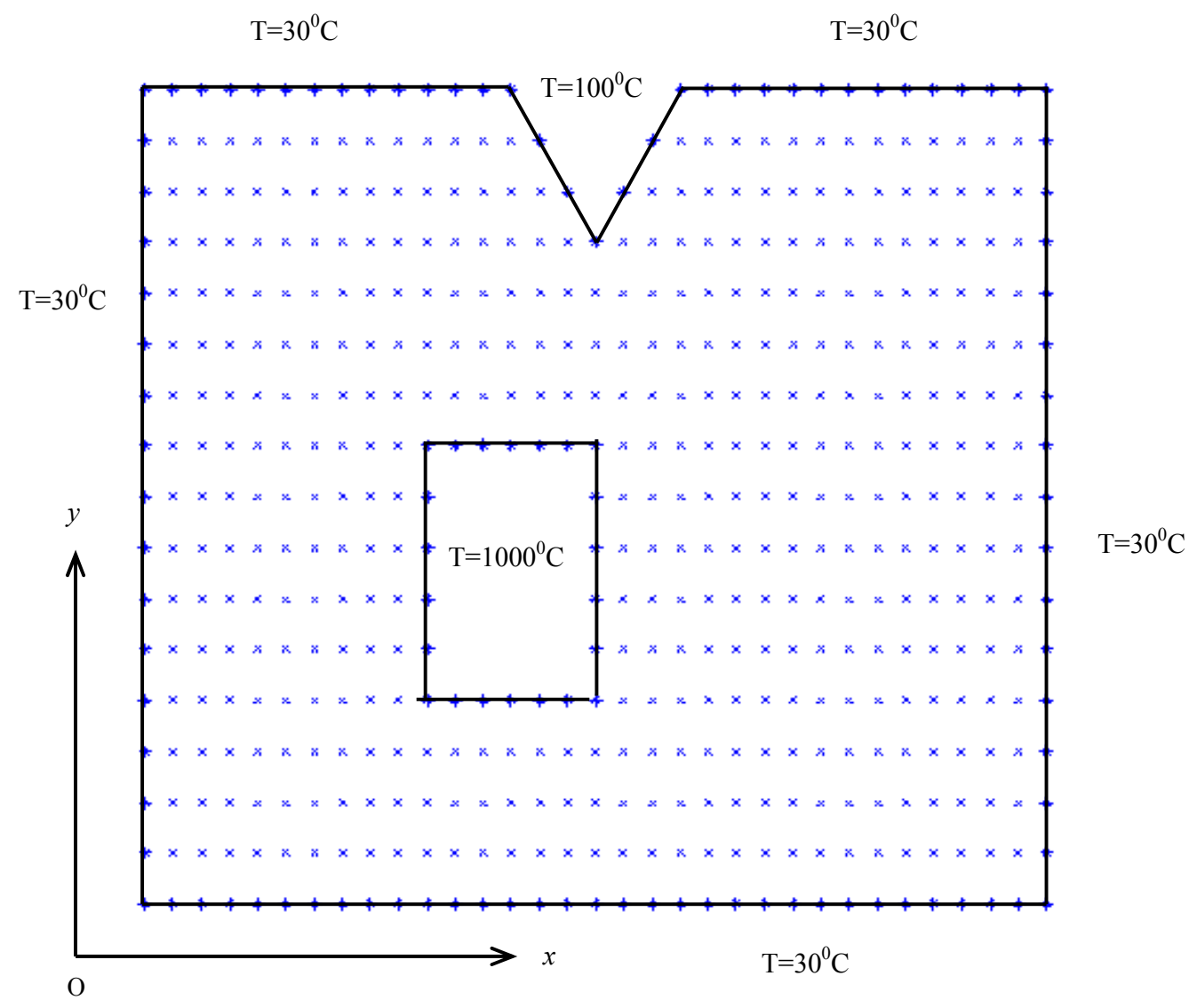

Fig.16. Boundary conditions of the aluminum plate having a notch on the top surface and a rectangular slot inside the plate. 


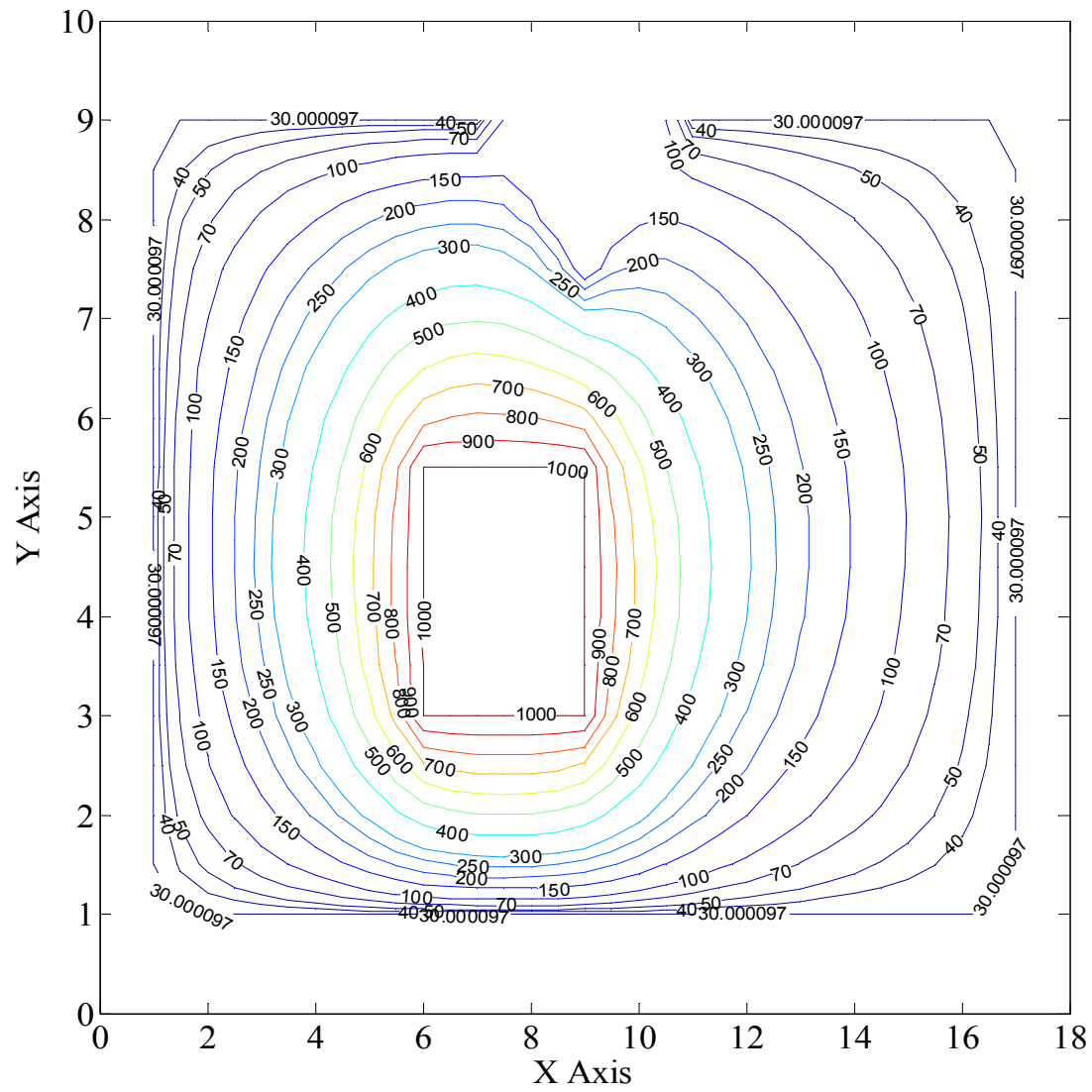

Fig.17. Contour plot of the distribution of temperature throughout the plate according to the problem mentioned in Fig.16.

$\mathrm{T}=30^{\circ} \mathrm{C}$

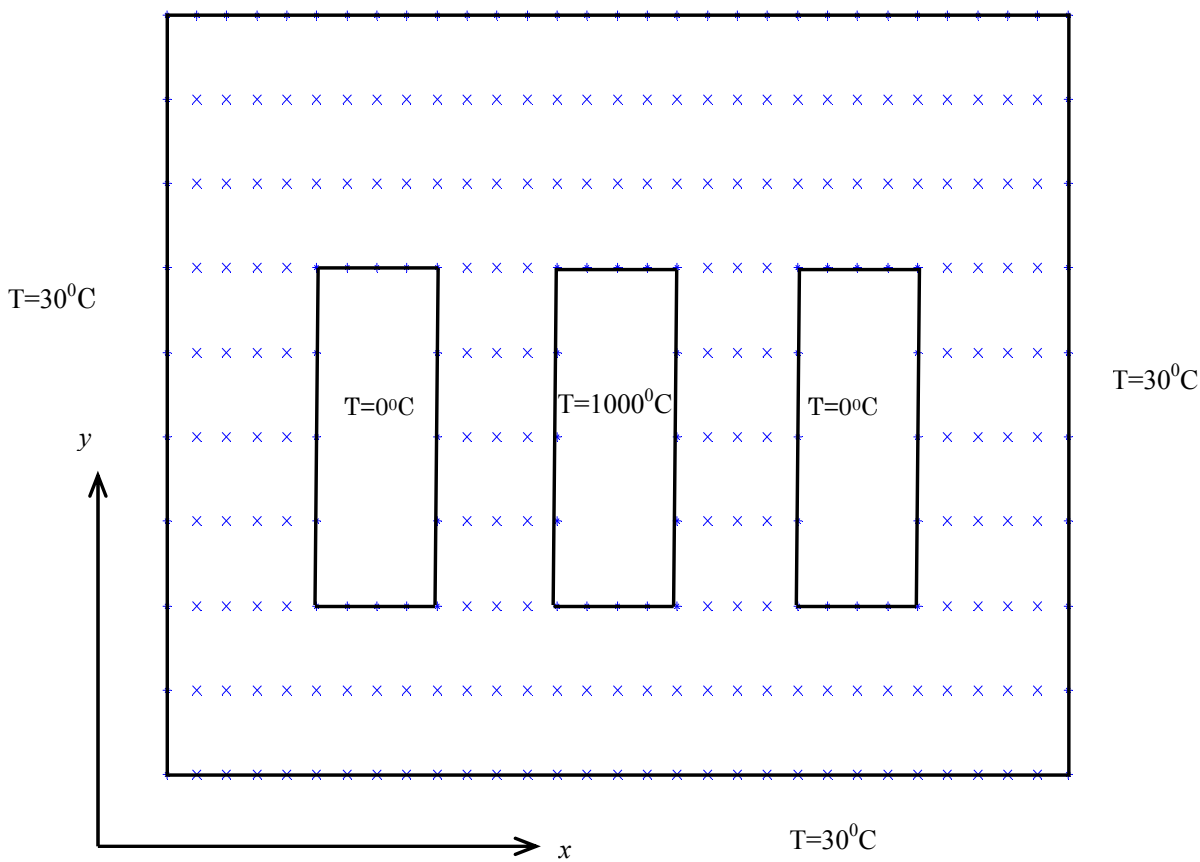

Fig.18. Boundary conditions of the aluminum plate having three slots inside the plate (Case 1). 


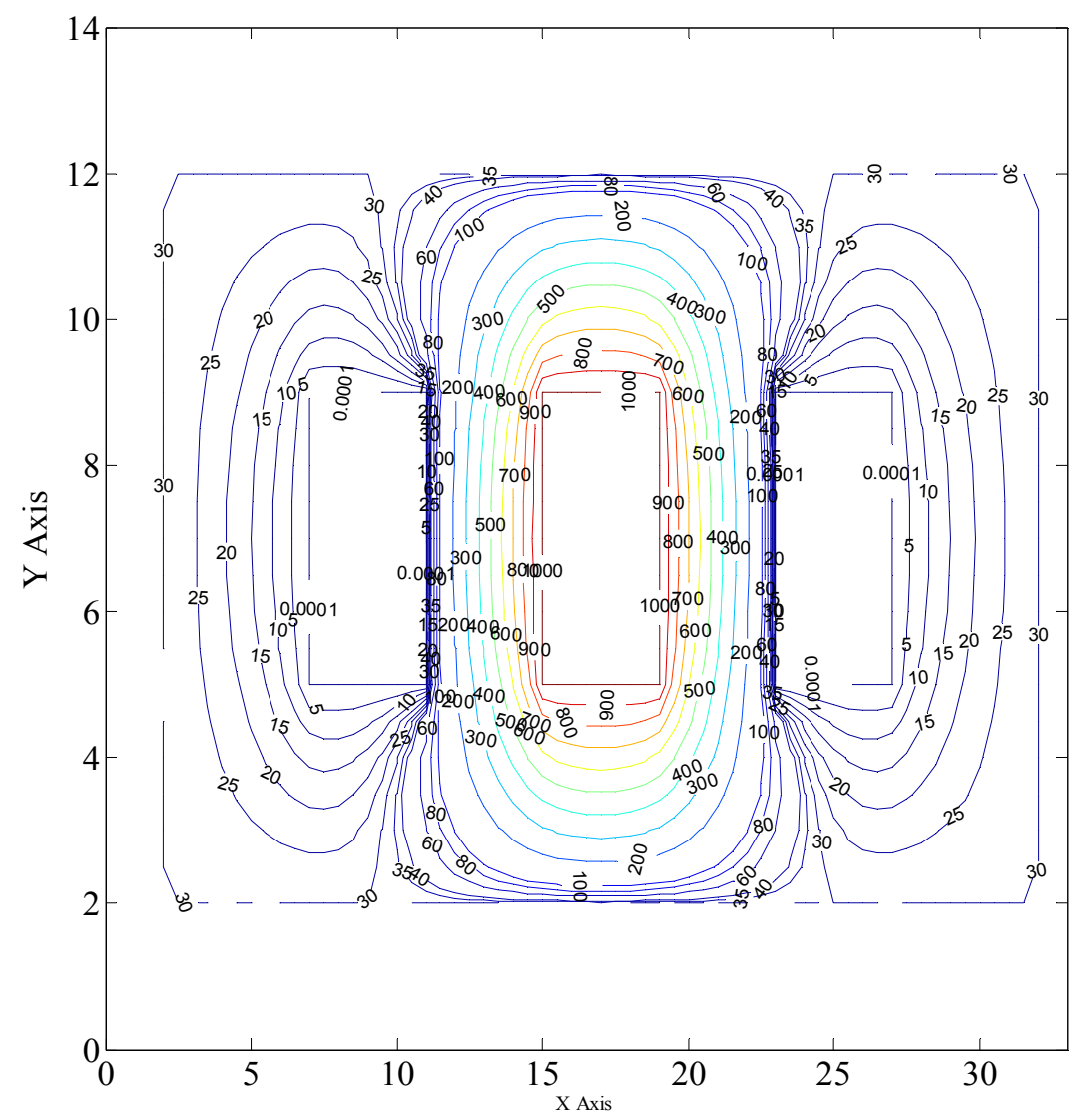

Fig.19. Contour plot of the distribution of temperature of the plate as shown in Fig.18.

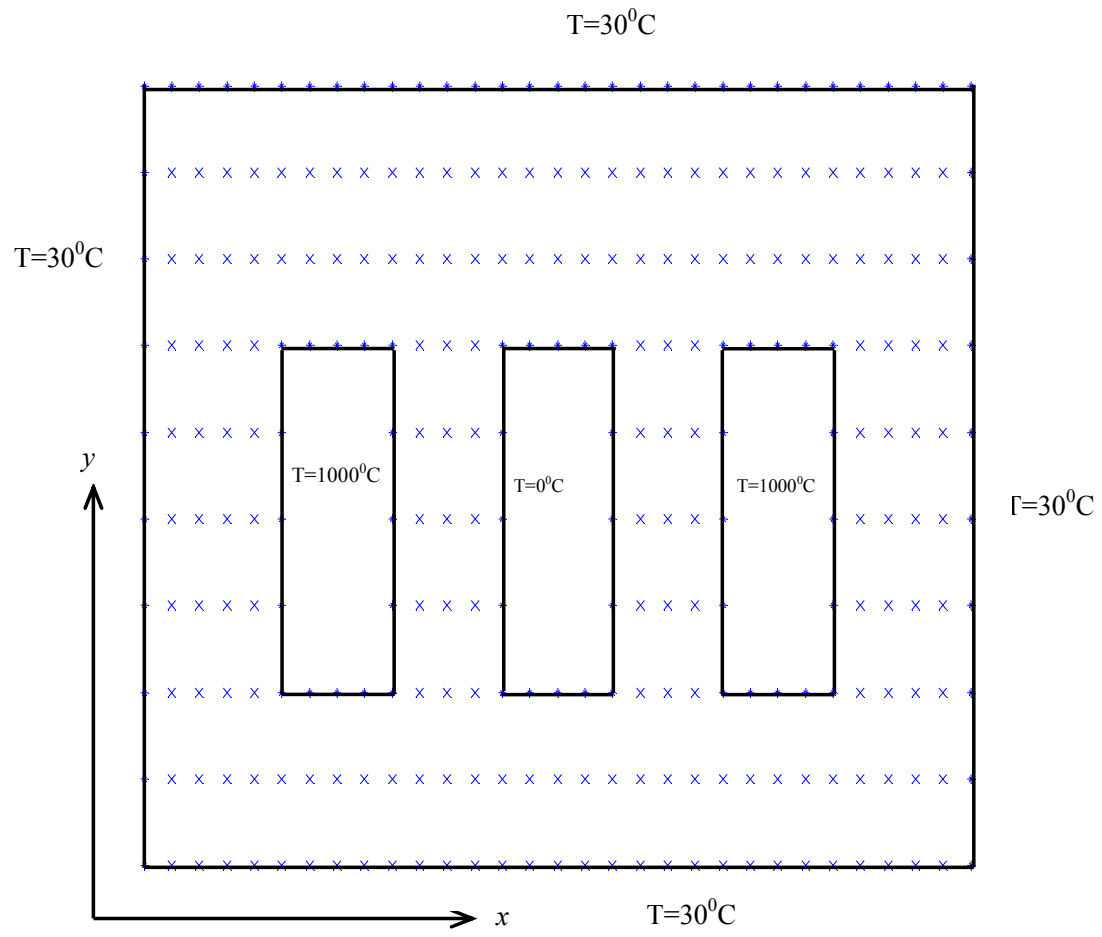

Fig.20. Boundary conditions of the aluminum plate having three slots inside the plate (Case 2). 


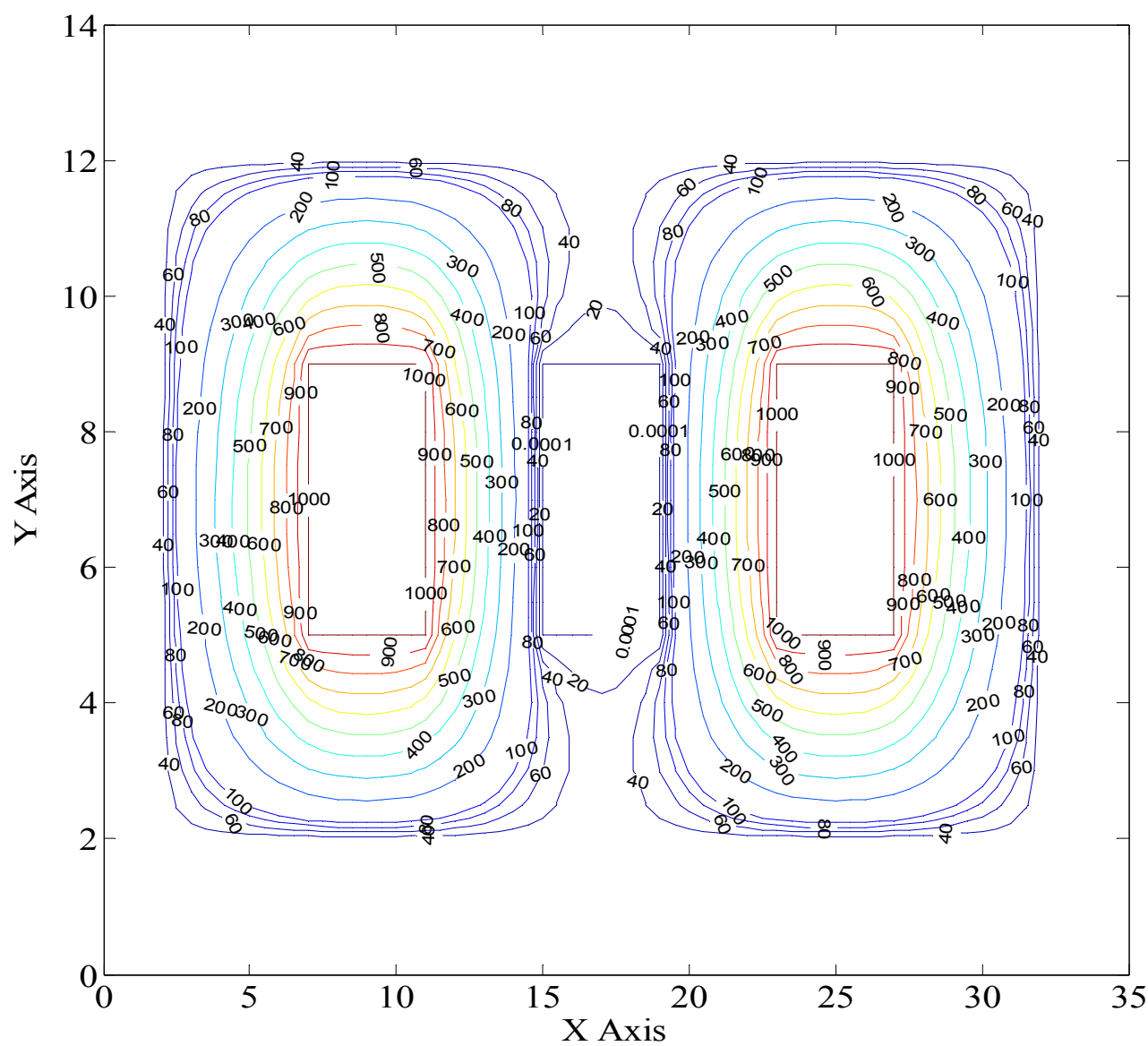

Fig.21. Contour plot of the distribution of temperature of the plate as shown in Fig.20.

Table 2. Required time to reach the steady state considering the transient phenomena as shown in Fig.6.

\begin{tabular}{|c|c|}
\hline Materials & Time taken to rich steady state (hr) \\
\hline Aluminum & 60 \\
\hline Stainless steel & 504 \\
\hline Copper & 52 \\
\hline Lead & 211 \\
\hline Tin & 134 \\
\hline Tungsten & 85 \\
\hline Silver & 36 \\
\hline Chromium & 179 \\
\hline Zinc & 127 \\
\hline
\end{tabular}

\section{Conclusion}

To verify the soundness of the solution of a $2 \mathrm{D}$ heat conduction problem obtained by the present finite difference technique, the analytical solutions of some sections of the plate with mixed boundary conditions are compared with the distribution of temperature of those sections of the plate obtained by the present finite difference method and the temperature distributions of some sections obtained by both of the 
methods agree well. So, the temperature distributions of some practical 2D heat conduction problems obtained by the present finite difference method are reliable. Firstly, a 2D aluminum plate with mixed boundary conditions is solved using the transient heat conduction approach to understand the time dependent temperature distribution at different sections of the plate. The transient heat conduction phenomenon in a plate is studied considering different materials. Secondly, an optimum mesh size is determined by varying the mesh density of a $2 \mathrm{D}$ rectangular heat conduction plate to solve the present problems. Thirdly, the same rectangular heat conduction plate is solved considering without the interpolation technique when the boundary of the plate passes through the meshing of the plate. Then this problem is solved considering interpolation technique when the boundary of the plate does not match the discretized grids of the plate. The temperature distribution on the boundary of an aluminum plate does not change if the interpolation technique is used to solve it when the boundary does not match with the regular grid network. Then a notch is introduced on the top of the plate and hot fluid is passed through it and effects of hot fluid on the temperature distribution near the notch are discussed. Then this problem is extended to introduce a rectangular slot inside it. Effects of slots and notches on the temperature distribution of the plate are clearly observed. Besides, three rectangular slots are introduced inside the rectangular plate. Effects of the hot and cold fluid passing through it on the temperature distribution of the plate are also analyzed.

\section{Nomenclature}

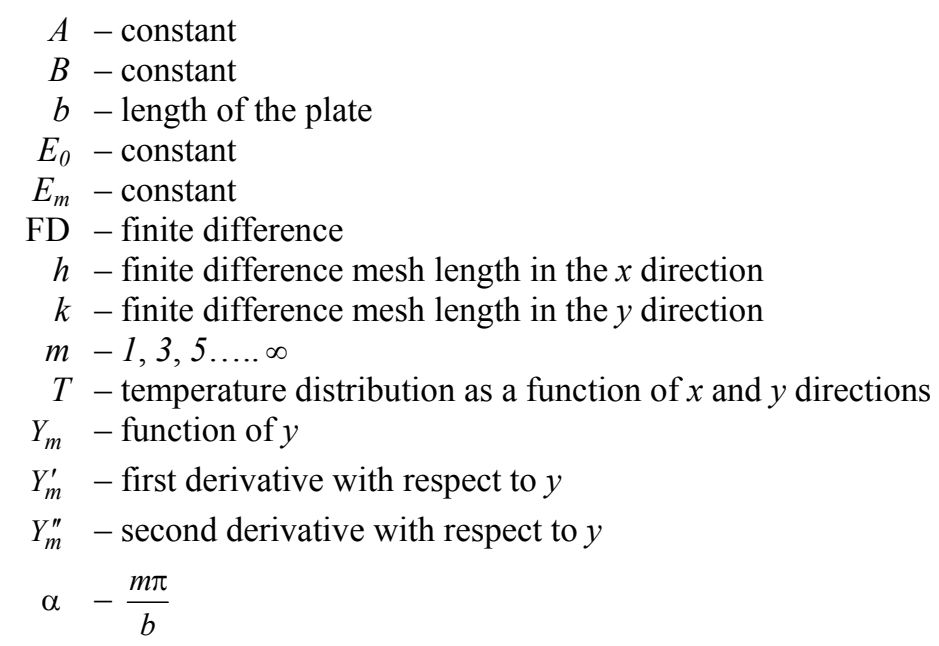

\section{References}

Ahmed S.R. and Deb Nath S.K. (2009): A simplified analysis of the tire-tread contact problem using displacement potential based finite difference. - Computer Modelling in Engineering and Sciences, vol.44, pp.35-64.

Ahmed S. Reaz, Deb Nath S.K. and Uddin M.W. (2005): Optimum shapes of tire treads for avoiding lateral slippage between tires and roads. - Vol.64, pp.729-750.

Battaner E. (1996): Astrophysical Fluid Dynamics. - Cambridge: Cambridge University Press.

Beck J.V. (1968): Determination of undisturbed temperatures from thermocouple measurements using correction Kernels. - Nucl. Eng. Design, vol.7, pp.9-12.

Beck J.V. (1970): Nonlinear estimation applied to non-linear inverse heat conduction problem. - Intl. J. Heat Mass Transfer, vol.13, pp.703-716.

Beck J.V., Blackwell B. and Clair C.R.S. (1985): Inverse Heat Conduction. - New York: Wiley.

Blackwell B.F. (1990): Temperature profile in semi-infinite body with exponential source and convective boundary condition. - J. Heat Transfer, vol.112, pp.567-571. 
Blomberg T. (1990): HEAT2- A heat transfer PC-program. - Proceeding of the $2^{\text {nd }}$ Conference on Building Physics in the Nordic Countries, Division of Building Technology, Department of Civil Engineering, The Norwegian Institute of Technology, The University of Tronheim, Alfr, Getz vei3, N-7034 Trondheim, Norway.

Blomberg T. (1991): HEAT2- A heat transfer PC-program. - Manual for HEAT2, Department of building physics, Lund University, P.O. Box 118, S-221 00 Lund, Sweden, CoDEN: LUTVDG/(TVBH-7122).

Blomberg T. (1993): HEAT3-A three-dimensional heat transfer computer program. - Proceeding of the $3^{\text {rd }}$ conference on building physics in the Nordic countries, Buiding Physics '93 (Bjarne Saxhof, editor), page 339, Thermal Insulation laboratory, Lyngby, Denmark, ISBN 87-984610-0-1 volume 1.

Blomberg T. (1994): HEAT3-A three-dimensional heat transfer computer program Manual for HEAT3. - Department of building physics, Lund University, P.O.Box. 118, S-221 00 Lund, Sweden. CODEN: LUTVDG/(TVBH-7169).

Blomberg T. (1994): HEAT2R-A PC-Program for heat conduction in cylindrical coordinates $r$ and $z$. - Department of Building Physics, LUND University. P.O. BOX 118, S-221 00 Lund, Sweden CODEN: LUTVDG/(TVBH-7178).

Burmeister L.C. (1993): Convective Heat Transfer. $-2^{\text {nd }}$ Ed., New York: Wiley.

Chen C.L. and Lin Y.C. (1998): Solution of two boundary problems using the differential transform method. - J. Optim. Theory, Appl., vol.99, pp.23-35.

Ching-China J. and Horng.-Yung J. (1998): Experimental investigation in inverse heat conduction problem. Numerical Heat Transfer, Part A, vol.34, pp.75-91.

Jaeger J.C. (1950): Conduction of heat in a solid with a power law of heat transfer at its surface. - Proc. Camb. Phil. Soc., vol.46, pp.634-641.

Deb Nath S.K. (2002): A study of wear of tire treads. - MSc. Thesis, Department of Mechanical Engineering, Bangladesh University of Engineering and Technology, Dhaka, Bangladesh.

Deb Nath S.K. (2008): Displacement potential approach to solution of stiffened composite cantilever beams under combined loading. - International Journal of Applied Mechanics and Engineering, vol.13, No.1, pp.21-41.

Deb Nath S.K. (2013): Effects of fiber orientation and material isotropy on the analytical elastic solution of a stiffened orthotropic panel subjected to a combined loading. - Advances in Materials Science and Engineering, vol.2013, Article ID 710143,13 pages.

Deb Nath S.K., Ahmed S.R. and Afsar A.M. (2006): Displacement potential solution of short stiffened flat composite bars under axial loading. - International Journal of Applied Mechanics and Engineering, vol.11, No.3, pp.557-575.

Deb Nath S.K., Afsar A.M. and Ahmed S.R. (2007): Displacement potential solution of a deep stiffened cantilever beam of orthotropic composite material. - Journal of Strain Analysis for Engineering Design, vol.42, No.7, pp.529540 .

Deb Nath S.K., Afsar A.M. and Ahmed S.R. (2007): Displacement potential approach to the solution of stiffened orthotropic composite panels under uniaxial tensile load. - Proceedings of the Institution of Mechanical Engineers, Part G: Journal of Aerospace Engineering, vol.221, No.5, pp.869-881.

Deb Nath S.K. and Ahmed S.R. (2008): Analytical solution of short guided orthotropic composite columns under eccentric loading using displacement potential formulation. - Proceedings of the Institution of Mechanical Engineers, Part G: Journal of Aerospace Engineering, vol.222, No.4, pp.425-434.

Deb Nath S.K. and Afsar A.M. (2009): Analysis of the effect of fiber orientation on the elastic field in a stiffened orthotropic panel under uniform tension using displacement potential approach. - Mechanics of Advanced Materials and Structures, vol.16, No.4, pp.300-307.

Deb Nath S.K. and Ahmed S.R. (2009): Displacement potential solution of stiffened composite struts subjected to eccentric loading. - Applied Mathematical Modelling, vol.33, No.3, pp.1761-1775.

Deb Nath S.K. and Ahmed S.R. (2009): Elastic analysis of short orthotropic composite columns subjected to uniform load over a part of the tip. - Proceedings of the Institution of Mechanical Engineers, Part G: Journal of Aerospace Engineering, vol.223, No.2, pp.95-105. 
Deb Nath S.K., Ahmed S.R. and Kim S.-G. (2010): Analytical solution of a stiffened orthotropic plate using alternative displacement potential approach. - Proceedings of the Institution of Mechanical Engineers, Part G: Journal of Aerospace Engineering, vol.224, No.1, pp.89-99.

Deb Nath S.K., Akanda M.A.S., Ahmed S.R. and Uddin M.W. (2008): Numerical investigation of bond-line stresses of tire tread section. - International Journal of Applied Mechanics and Engineering, vol.13, pp.43-61.

Deb Nath S.K., Ahmed S.R., Kim S-G. and Wong C.H. (2011): Effect of tire material on the prediction of optimum tire tread sections. - International Journal for computational methods in Engineering Science and Mechanics, vol.12, 290-302.

Grewal M.S. (1986): Application of Kalman filtering to the calibration and alignment of inertial navigation systems.presented at PLANS '86- position location and Navigation Symposium, Las Vegas, Nevada.

Jordan P.M. (2003): A nonstandard finite difference scheme foe non-linear heat transfer in a thin finite rod. - Journal of Difference Equations and Applications, vol.9, pp.1015-1021.

Kalman R.E. (1960): A new approach to linear filtering and prediction problems. - ASME J. Basic Eng., ser. 82d, pp.35-45.

Lo C-Y (2011): A study of two-step heat conduction in laser heating using the hybrid differential transform method. Numerical Heat Transfer, Part B, vol.59, pp.130-146.

Mohiuddin M., Uddin M.W., Deb Nath S.K. and Ahmed S.R. (2012): An alternative numerical solution to a screwthread problem using displacement-potential approach. - International Journal for Computational Methods in Engineering Science and Mechanics, vol.13, pp.254-271.

Özisik M.N. (1989): Boundary Value Problems of Heat Conduction. - New York: Dover.

Peng H-S and Chen C.L. (2011): Application of hybrid differential transformation and finite differential transformation and finite difference method on the laser heating problem. - Numerical Heat Transfer, Part A, vol.59, pp.28-42.

Scarpa F. and Milano G. (1995): Kalman smoothing technique applied to the inverse heat conduction problem. Numer. Heat Transfer, part B, vol.28, pp.79-96.

Siegel R. and Howell J.H. (1972): Thermal Radiation Heat Transfer. - New York: McGraw-Hill.

Stolz Jr.G. (1960): Numerical solutions to an inverse problem of heat conduction for simple shapes. - ASME J. Heat Transfer, vol.82, pp.20-26.

Zongrui L. and Zhongwu L. (1994): A control theory method for solutions of inverse transient heat conduction problems. - Trans. ASME, vol.116, pp.228-230.

Yu L.T. and Chen C.K. (1998): The solution of the Blasius equation by the differential transform method. - Math. Comput. Model, vol.28, pp.101-111.

Received: July 17, 2014

Revised: September 17, 2015 